Article

\title{
The TZM-b1 Reporter Cell Line Expresses Kynureninase That Can Neutralize 2F5-like Antibodies in the HIV-1 Neutralization Assay
}

\author{
Vladimir Morozov $1,2, *\left(\mathbb{D}\right.$, Sylvie Lagaye ${ }^{3(\mathbb{D})}$ and Alexey Morozov $4, *(\mathbb{D})$ \\ 1 Institute of Human Virology, University of Maryland, Baltimore, MD 21201, USA \\ 2 Department of Infectious Diseases, Robert Koch Institute, 13353 Berlin, Germany \\ 3 Centre de Recherche Saint-Antoine (CRSA), INSERM-UMR-S 938/Sorbonne Université, CEDEX 12, \\ 75571 Paris, France; sylvie.lagaye@inserm.fr \\ 4 Laboratory of Regulation of Intracellular Proteolysis, Engelhardt Institute of Molecular Biology, \\ Russian Academy of Sciences, 119991 Moscow, Russia \\ * Correspondence: Morvlad@hotmail.com (V.M.); Runkel@inbox.ru (A.M.)
}

Citation: Morozov, V.; Lagaye, S.; Morozov, A. The TZM-bl Reporter Cell Line Expresses Kynureninase That Can Neutralize 2F5-like Antibodies in the HIV-1 Neutralization Assay. Int. J. Mol. Sci. 2022, 23, 641. https://doi.org/ 10.3390/ijms23020641

Academic Editor: Nuno Taveira

Received: 7 December 2021

Accepted: 5 January 2022

Published: 7 January 2022

Publisher's Note: MDPI stays neutral with regard to jurisdictional claims in published maps and institutional affiliations.

Copyright: (C) 2022 by the authors. Licensee MDPI, Basel, Switzerland. This article is an open access article distributed under the terms and conditions of the Creative Commons Attribution (CC BY) license (https:// creativecommons.org/licenses/by/ $4.0 /)$.

\begin{abstract}
Induction of broadly neutralizing antibodies targeting ectodomain of the transmembrane (TM) glycoprotein gp41 HIV-1 provides a basis for the development of a universal anti-viral vaccine. The HeLa cell-derived TZM-bl reporter cell line is widely used for the estimation of lentiviruses neutralization by immune sera. The cell line is highly permissive to infection by most strains of HIV, SIV, and SHIV. Here we demonstrated that TZM-bl cells express a $48 \mathrm{kDa}$ non-glycosylated protein (p48) recognized by broadly neutralizing monoclonal antibody (mAb) 2F5 targeting the ELDKWA (aa 669-674) epitope of gp41TM of HIV-1. A significant amount of p48 was found in the cell supernatant. The protein was identified as human kynureninase (KYNU), which has the ELDKWA epitope. The protein is further called "p48 KYNU". The HIV-1 neutralization by mAb 2F5 and 4E10 in the presence of p48KYNU was tested on Jurkat and TZM-bl cells. It was demonstrated that p48KYNU reduces neutralization by 2F5-like antibodies, but it has almost no effect on mAb 4E10. Therefore, p48KYNU can attenuate HIV-1 neutralization by 2 F5-like antibodies and hence create false-negative results. Thus, previously tested immune sera that recognized the ELDKWA-epitope and demonstrated a "weak neutralization" of HIV-1 in TZM-bl assay should be reevaluated.
\end{abstract}

Keywords: TZM-bl cell line; HIV-1; mAb 2F5; mAb 4E10; sera; neutralization assay; kynureninase; expression

\section{Introduction}

HeLa cells and HeLa-derived modified cell lines are the most frequent in vitro models that are used for diverse biomedical applications. Compared to the 16 tissues from Illumina Human BodyMap 2.0 in the HeLa Kyoto cell line there are about 1900 highly expressed genes and above 5000 genes that are downregulated or not expressed [1]. Indeed, modifications of the HeLa cells using integrating vectors may result in activation of additional cellular genes and expression of an extra protein(s). Most likely the protein(s) would not interfere with a newly designed cell function. Though, in some instances, the interference might take place.

The TZM-bl reporter cell line (NIH AIDS Reagent program \#8129, also called JC57BL13) was engineered from HeLa cells by amphotropic retroviral transduction to express CD4, CXCR4, and CCR5 [2]. Then cells were transfected with two lentiviral vectors coding for the reporter genes-firefly luciferase [3] and E. coli $\beta$-galactosidase under control of the HIV-1 LTR [4,5]. After infection of TZM-bl cells, reverse transcription, and integration of viral cDNA, the Tat protein is synthesized from viral transcripts and triggers the expression of introduced reporter genes in cells. The activity of the $\beta$-galactosidase may be measured 
using different assays reflecting the number of cells that turn blue after X-gal staining and the activity of luciferase is quantified by the luminescence intensity that is proportional to the number of infectious viruses present in the examined specimen. Altogether, the cell line is a sensitive and easy diagnostic tool that is widely used to estimate HIV, SIV, and SHIV infectious titer and to evaluate the neutralization (NT) potency of tested sera [6-21]. It has been shown that TZM-bl cells are infected with ecotropic gamma-retrovirus [22]. However, this contamination does not influence the "reporter ability" of the cell line [23]. Not long ago the protocol of HIV-1 neutralizing antibody testing on TZM-bl cells was optimized and the test was validated by several laboratories [24].

Broadly neutralizing monoclonal antibody $(\mathrm{mAb}) 2 \mathrm{~F} 5$ recognizes epitope ELDKWA in the membrane proximal external region (MPER) of transmembrane (TM) protein gp41 of HIV-1 $[25,26]$. MAb 2F5 is frequently used in biochemical, diagnostic, and immunological studies. The antibody was used in passive immunization trials $[27,28]$ and protection studies using adeno-associated virus with inserted genes encoding neutralizing antibodies that demonstrate promising results [29]. An HIV vaccine inducing a high titer of 2F5-like broadly neutralizing antibodies would be a fundamental achievement in the fight against AIDS. However, till now all attempts to design such a vaccine were unsuccessful.

Here we identified and characterized a protein that is expressed and secreted from the TZM-bl cells and interferes with mAb 2F5 in the HIV-1 neutralization assay.

\section{Results}

\subsection{Detection and Characterization of $p 48$ from TZM-bl Cells}

To study possible non-specific interaction of $\mathrm{mAb} 2 \mathrm{~F} 5$ with cellular proteins, lysates of seven cell lines were tested using Western blot analyses. Only in the case of TZM-bl cells, a strong reaction with the $48 \mathrm{kDa}$ protein (p48) was observed (Figure 1a). To examine the consistency of the p48 expression in TZM-bl cells, lysates of cells harvested after passages $\# 10$ and \#25 were compared by Western blot analysis using mAb 2F5. Both lysates contained equal amounts of proteins (Figure S1). To demonstrate that p48 and gp41TM of HIV-1 are different proteins, a comparative Western blot analysis was performed using HIV- $1_{\mathrm{pNL4}-3}$ purified on $20 \%$ sucrose cushion, cellular lysates of $293 \mathrm{~T}$ cells transfected with pNL4-3 (positive control) and cellular lysate of TZM-bl cells. It was shown that the protein mass is different. However, mAb 2F5 reacted with p48 and gp41 equally strong (Figure 1b). Next, we examined the distribution of p48 in five TZM-bl cell lines from three laboratories (Figure 1c, tracks 3 to 5). Cell lines were examined after passage \#10 (Figure 1c, track 2) and passage \#3 (Figure 1c, track 6) after receiving from the NIH AIDS Reagent Program. The passage number of the other three cell lines originally also obtained from $\mathrm{NIH}$ was unknown. All cellular lysates contained p48, indicating that the protein expression in TZM-bl cells is ubiquitous. Afterwards, we analyzed the p48 localization in cells. Extracted cytoplasmic and nuclear fractions of TZM-bl cells were tested by Western blot analysis with $\mathrm{mAb} 2 \mathrm{~F} 5$. The p48 was detected only in the cytoplasmic fraction (Figure 1d, track 4). Further on, oligomerization of $\mathrm{p} 48$ was assessed using a cytoplasmic fraction of TZM-bl cells. Protein electrophoresis was performed in native $4-20 \%$ gradient gel. Performed Western blot analyses demonstrated that the protein is forming dimers (Figure 1e, track 2). 


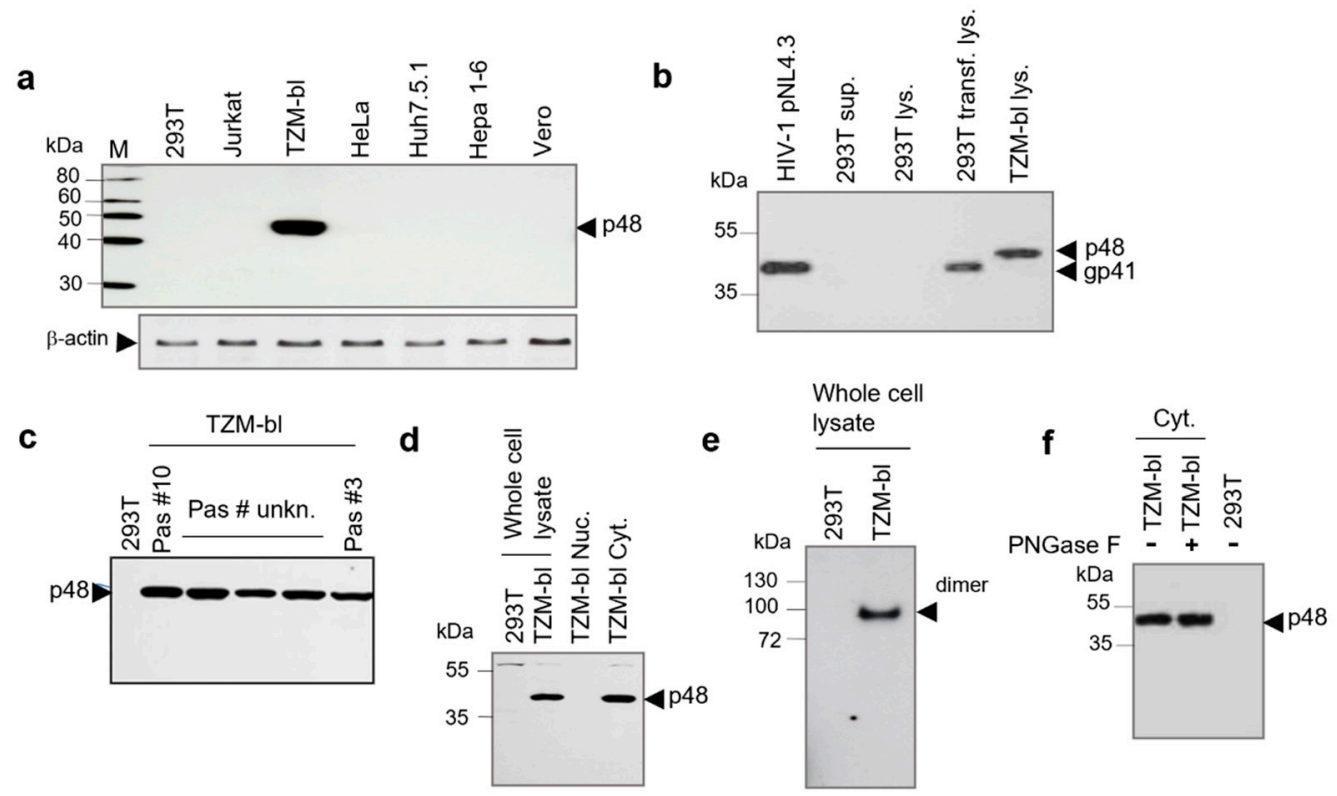

Figure 1. Detection and characterization of the $48 \mathrm{kDa}$ protein (p48) from TZM-bl cells. (a) Comparative analyses of established cell lines lysates by Western blotting. Low panel - blot treated with $\mathrm{mAb}$ anti- $\beta$-actin. (b) Comparison of Mab 2F5 reactivity with gp41 HIV-1 and p48 by Western blot analysis.

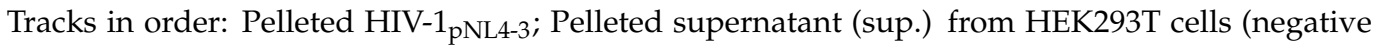
control); Lysate (lys.) of non-transfected HEK293T cells (negative control); Lysate of HEK293T cells

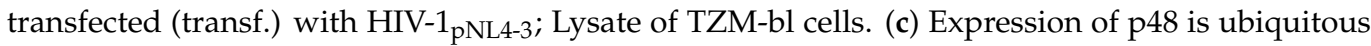
in TZM-bl cell lines obtained from different sources. Whole-cell lysates of TZM-bl cells passage $\# 10$ and \#3 following receiving from NIH and lysates from cells obtained from three laboratories (unknown passage numbers following receiving from NIH) were analyzed by Western blot. HEK293T cells whole-cell lysate was used as a negative control. (d) Comparative Western blot analysis of nuclear (Nuc.) and cytoplasmic (Cyt.) fractions. The protein was detected in the cytoplasmic fraction. (e) Dimerization of p48 was analyzed using native gradient PAGE followed by Western blot analysis using HEK293T and TZM-bl whole cell lysates. The position of the p48 dimer is indicated. (f) The p48 protein is not glycosylated as shown by the PNGase F treatment of TZM-bl cytoplasmic fraction (Cyt.). HEK293T whole cell lysate was used as a negative control. Western blots were treated with $\mathrm{mAb} 2 \mathrm{~F} 5(2.5 \mathrm{mg} / \mathrm{mL}$ ) and anti-human IgG conjugated with HRP (dilution 1:10 K). M-Size markers (Magic Mark XP standard, Invitrogen) and PageRuler Plus protein ladder (ThermoFisher Scientific, Waltham, MA, USA) were used for calibration.

To access the protein glycosylation, the cellular lysate was treated with peptide-NGlycosidase (PNGase F). As shown by Western blot analysis mobility of the protein was not changed, indicating a lack of $N$-glycosylation (Figure 1f). Altogether, performed tests showed that $\mathrm{p} 48$ is a cytoplasmic, non-glycosylated protein that in native conditions forms homodimers. It should be emphasized, that no immune reactivity against $\mathrm{p} 48$ was detected by Western blot analysis when TZM-bl cellular lysates were examined using mAb 4E10 and Chessie 8 (Figure S2), that target other than 2F5 regions of gp41 HIV-1.

\subsection{Analysis of the 448 in Cells by Confocal Microscopy and Isolation of $p 48$ from Cell-Free Supernatant}

The p48 localization in TZM-bl cells was accessed by confocal microscopy (Figure 2a). The TZM-bl cells were fixed and stained with mAb $2 \mathrm{~F} 5(5 \mu \mathrm{g} / \mathrm{mL})$, followed by treatment with anti-human Alexa 488 conjugated antibodies. The protein was found in the cytoplasm with no evident association with the plasma membrane. Interestingly a high concentration of p48 was found in blebs and extracellular vesicles of various sizes $(\sim 0.4-1 \mu \mathrm{m})$ (Figure 2a). Such vesicles were not detected in HEK293T cells (Figure 2b). The sizes of vesicles corre- 
spond to that of shedding microvesicles (MVs) that are ranging from $100 \mathrm{~nm}$ to $1000 \mathrm{~nm}$ in diameter. While exosomes are generally smaller $(<100 \mathrm{~nm})$ [30].
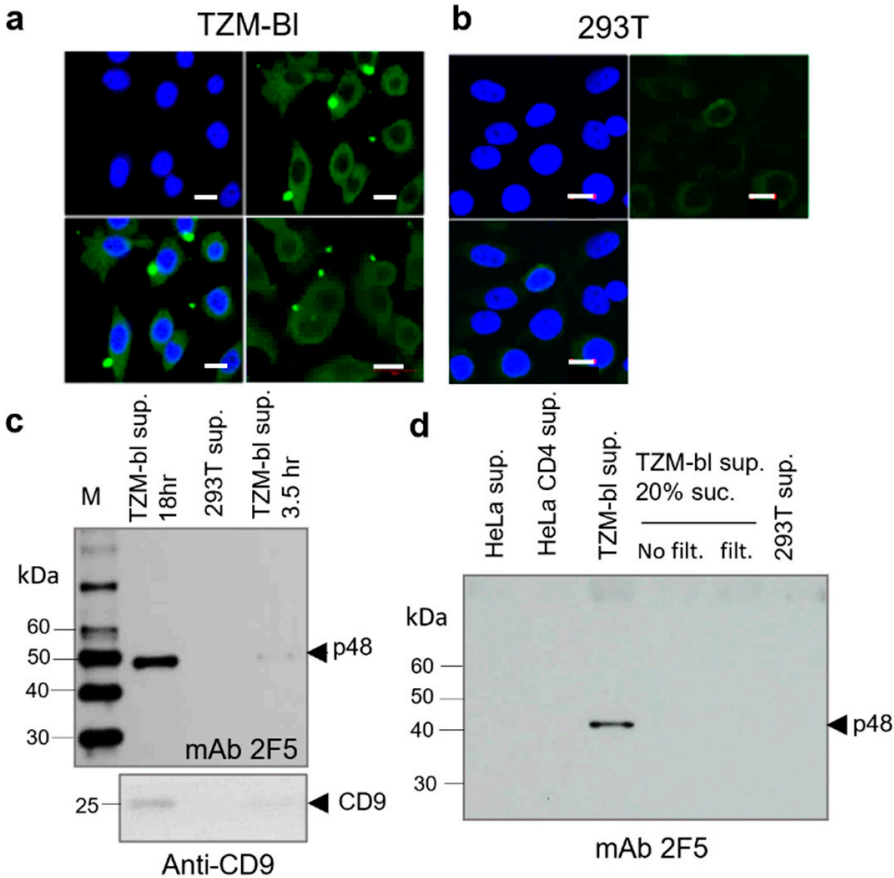

Figure 2. Confocal microscopy of TZM-bl cells revealed blebs and bright extracellular vesicles containing $\mathrm{p} 48$. Isolation of $\mathrm{p} 48$ from the cell supernatant. Confocal microscopy. The TZM-bl (a) and HEK293T (b) cells were fixed, stained with mAb 2F5 (5 $\mathrm{gg} / \mathrm{mL})$, and treated with anti-human Alexa 488 conjugated antibodies. Cell nuclei were stained with DAPI. Scale bar $=10 \mu \mathrm{m}$. Green blebs and extracellular vesicles were found in association with TZM-bl cells. (c) Detection of p48 in the supernatant of TZM-bl cells grown on SFM. Pelleted serum-free supernatant from TZM-bl cells after high-speed centrifugation $(170,000 \times \mathrm{g})$ for $18 \mathrm{hr}$ and $3.5 \mathrm{hr}$ and pellet from the supernatant of HEK293T cells after $18 \mathrm{~h}$ of centrifugation were analyzed by Western blot. (Low panel) Detection of CD9 in pelleted supernatants. Blot was treated with anti-human CD9 mAbs in dilution 1:750. (d) p48 released also as a free protein. Cell supernatants were centrifuged at $1500 \times g$, at $10,000 \times g$, and overnight at $170,000 \times g$. Tracks in order: Supernatant (sup.) from HeLa cells (overnight centrifugation). Supernatant from HeLa CD4+LTR-Luc cells (HeLa CD4) overnight centrifugation; Supernatant from TZM-bl cells (overnight centrifugation); Supernatant from TZM-bl cells (no $0.45 \mu \mathrm{m}$ filtration (no filt.), overnight centrifugation through 20\% sucrose (suc.)); Supernatant from TZM-bl cells $(0.45 \mu \mathrm{m}$ filtration (filt.) and overnight centrifugation through $20 \%$ sucrose); Supernatant from 293T cells (overnight centrifugation). Western blot analyses were performed using mAb 2F5.

\subsection{Identification of p48 as Kynureninase (KYNU)}

The HXB2 molecular clone was used as a packaging construct in the design of the TZM-bl cell line. Lentiviral transfer vectors coding for the viral receptors and containing 234 nucleotide long RRE sequences (which overlap with gp41) were used in cell modification $[2,4,5]$. In this regard, we initially suggested that p48 might be coded by one of the mutated lentiviral transfer vectors that contained a fragment of the HIV-1 env gene. To detect HIV-1 env transcripts the RNA was extracted from TZM-bl and HEK293T cells (negative control) and tested by RT-PCR using two sets of primers (Table 1) targeting the $3^{\prime}$-end of gp120 and the gp41 ectodomain fragments. However, all attempts to detect the env transcripts have failed. Altogether, the absence of the env-like transcripts and lack of reactivity with human $\mathrm{mAb} 4 \mathrm{E} 10$ and mouse $\mathrm{mAb}$ Chessie 8 , allowed suggesting, that $\mathrm{p} 48$ is a cellular protein. Using bioinformatics, the gp41 HIV-1 ectodomain was examined for 
homology to cellular proteins and the only protein that has the ELDKWA epitope was human kynureninase (KYNU).

Table 1. Cell lines.

\begin{tabular}{ccc}
\hline Cell Lines & Origin & Cell Type/Morphology \\
\hline HeLa & NIH AIDS Reagent Program (\#153) & Human cervical carcinoma \\
HeLa CD4+LTR-Luc & Robert Koch Institute & Human cervical carcinoma \\
TZM-bl (HeLa-derived) & NIH AIDS Reagent Program (\#8129) & Human cervical carcinoma \\
Huh 7.5.1. & Scripps Res. Inst., San Diego, CA, USA & Human hepatocytes, \\
HepG2 & (Prof. Frank Chisari) & epithelial-like \\
Jurkat & ATCC, HB8065 & Human hepatocytes \\
Hepa 1-6 & NIH AIDS Reagent Program (\#177) & Human lymphocytes \\
Vero & ATCC, CRL-1830 & Mouse hepatoma \\
& NIH AIDS Reagent Program (CCL-81) & Grivet monkey, kidney
\end{tabular}

KYNU is a key enzyme on the kynurenine pathway of tryptophan metabolism. KYNU is a cytoplasmic, non-glycosylated protein of about $52 \mathrm{kDa}(48-50 \mathrm{kDa}$ in SDS-PAGE), that forms homodimers [31,32]. Accordingly, the parameters of p48 were like that of KYNU. Data from Human Protein Atlas (www.proteinallas.org, accessed on 15 March 2018) indicated that several cell lines including human hepatocellular carcinoma cell line HepG2, express KYNU. The crystal structure of KYNU is known [33]. It was found that both proteins contain the ELDKWA epitope. In KYNU the motive is in the H4 domain [34]. Alignments of amino acid fragments with ELDKWA epitopes of gp41 HIV-1 and KYNU (Figure 3a), and 3D models of the regions together with flanking amino acids are shown (Figure 3b). Interestingly, besides the ELDKWA epitopes, these proteins structurally are significantly different.

Next, we performed comparative analyzes of KYNU transcripts in TZM-bl and HepG2 cells. Transcripts from HEK293T and Huh 7.5.1 cells were used as negative controls. To analyze transcripts of p48 KYNU the RT-PCR targeted the $845 \mathrm{bp}$ long fragments with ELDKWA was performed. Corresponding amplicons were detected in both the TZM-bl and the HepG2 cells. The number of amplicons in TZM-bl cells was about 3-4 times higher compared to that of HepG2 (Figure 3c, upper panel). Analyses of sequenced clones demonstrated that KYNU fragments from TZM-bl cells and HepG2 cells were identical and showed 100\% identity to human KYNU sequences from the GenBank (NM_001032998, BC000879, NP_001028170.1, NM_003937,Q16719, etc.).

After that, the p48 KYNU protein expression in TZM-bl and KYNU in HepG2 cells were compared by Western blot analysis using mAb 2F5 (Figure 3c, low panel) and polyclonal anti-KYNU serum (Figure 3d, upper panel). The protein was detected in both cell lines. However, the amount of p48 KYNU in TZM-bl was about 8 times higher (estimated using ImageJ) than in HepG2 cells, while the total protein load was equal (Figure 3d, low panel). A significantly higher protein expression in TZM-bl cells might be attributed to the promotion of the KYNU gene expression by LTR from the integrated lentiviral vector. Noteworthy, comparison of polyclonal anti-KYNU serum and mAb 2F5 demonstrated equal reactivity with recombinant (rKYNU) and $\mathrm{p} 48 \mathrm{KYNU}$ when rabbit anti-KYNU was used in dilution (1:800) and $\mathrm{mAb} 2 \mathrm{~F} 5$ were diluted to $2.5 \mathrm{mg} / \mathrm{mL}$ (Figure S3a,b).

Lastly, the cDNA KYNU amplicon (845 bp) obtained from TZM-bl cells with a coding capacity of $36 \mathrm{kDa}$ was cloned in the expression vector pTargeT (Promega). HEK293T cells were transfected with the construct and $48 \mathrm{hr}$ later cellular lysates were prepared and examined for KYNU expression by Western blot analysis with anti-KYNU antibodies. The truncated variant - p36 KYNU, was recognized by anti-KYNU (Figure S4). The protein was used as a target antigen in several experiments (not shown). 
a

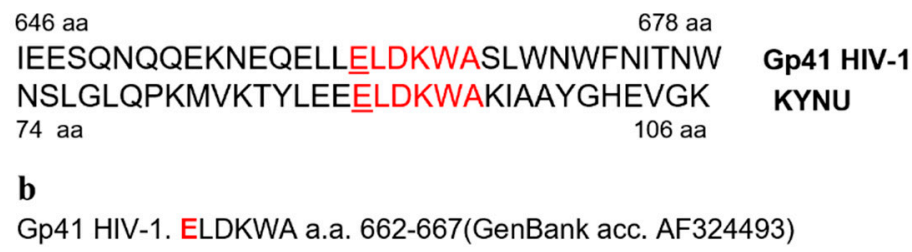

b

Gp41 HIV-1. ELDKWA a.a. 662-667(GenBank acc. AF324493)

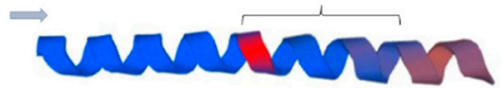

KYNU. ELDKWA a.a. 90-95 (GenBank acc. Q16719)

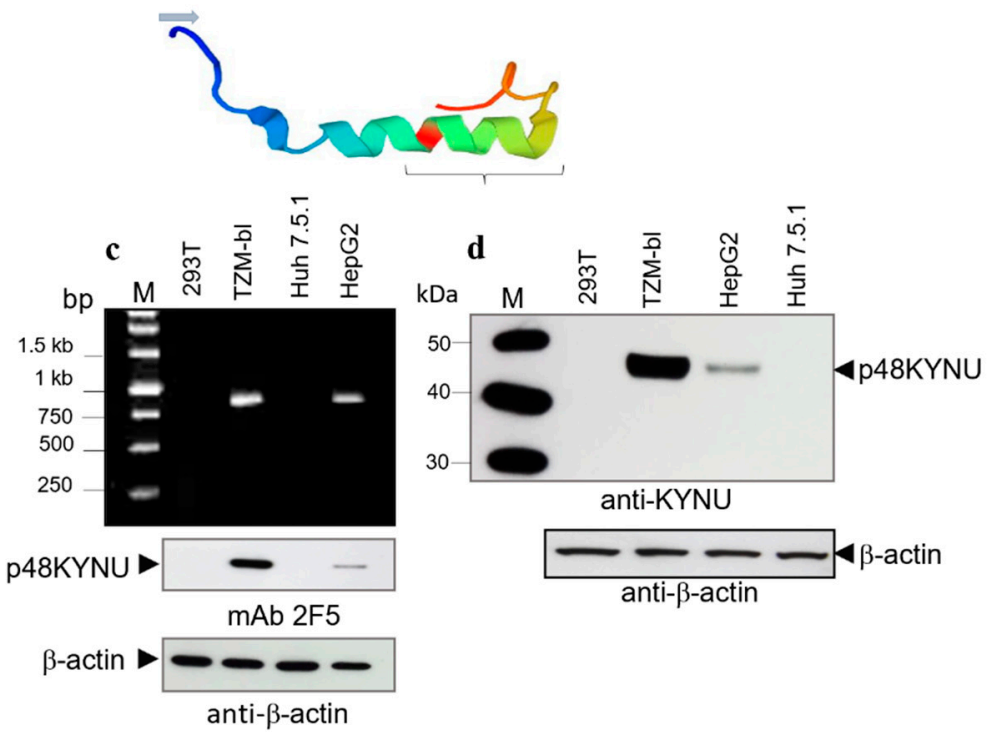

Figure 3. Identification of p48 as kynureninase (KYNU). Detection of p48 KYNU transcripts in TZM-bl cells and comparative analysis of KYNU protein content in TZM-bl and HepG2 cells. (a) Amino acid alignment of gp41 HIV-1 and KYNU fragments containing ELDKWA with flanking regions. (b) 3D models of gp41 HIV-1 and KYNU (a part of the H4 domain) amino acid fragments containing the ELDKWA epitopes. Blue arrowhead indicates the direction of reading. Braces marked the position of the ELDKWA motifs. Glutamic acids (E) in the ELDKWA epitopes are marked in red. (c) Upper panel. Detection of KYNU transcripts in different cell lines by RT-PCR. M-Markers (1 kb O'Gene Ruler). Low panel. Comparative analysis of KYNU in TZM-bl and HepG2 cellular lysates $\left(4 \times 10^{4}\right.$ cells $)$ by Western blot analysis. Samples are in the same order as on the upper panel. Equal protein load was confirmed by anti- $\beta$-actin staining. (d) Recognition of KYNU in both the TZM-bl cells and the HepG2 cells by anti-KYNU serum. M-Markers (MagicMark XP Standard). Upper panel. Western blot analysis. HEK293T cell lysate $\left(1 \times 10^{5}\right.$ cells); TZM-bl cell lysate $\left(1 \times 10^{5}\right.$ cells $)$; HepG2 cell lysate $\left(1 \times 10^{5}\right.$ cells $)$; Huh 7.5.1 cell lysate $\left(1 \times 10^{5}\right.$ cells $)$. Low panel. Equal protein load was confirmed by $\beta$-actin distribution. Western blot analyses were performed using $\mathrm{mAb} 2 \mathrm{~F} 5(2.5 \mathrm{mg} / \mathrm{mL})$, rabbit anti-KYNU (1:750), and anti- $\beta$-actin (1:1000).

Thus, obtained results explicitly demonstrated that the 488 protein in TZM-bl cells is a human kynureninase.

\subsection{Estimation of p48 KYNU Amount in TZM-bl Cells and Cell Supernatant}

Estimation of p48 KYNU content in cells and especially the amount of the protein released from cells were critical for the prediction of p48 KYNU potency to neutralize 2F5-like antibodies.

Initially, we estimated the amount of p48 KYNU in TZM-bl cells. Cells were grown in complete medium and were harvested after $48 \mathrm{~h}$. The p48 KYNU content in lysate from 
$5 \times 10^{4}$ TZM-bl cells was compared to serial two-fold dilutions (from $180 \mathrm{ng}$ to $22.5 \mathrm{ng}$ ) of T-20 (a 36 aa peptide with ELDKWA epitope) (Figure 4a). Comparative analysis using ImageJ showed that lysate of $5 \times 10^{4}$ cells contained about $32 \mathrm{ng}$ (or $4 \times 10^{11}$ molecules) of p48 KYNU. That amount corresponds to $0.64 \mathrm{pg}$ or $0.8 \times 10^{7}$ molecules/cell. Evidently, this amount is lower than the amount of p48 KYNU in cells, as a part of the molecules might be captured and pelleted together with cellular debris during centrifugation.

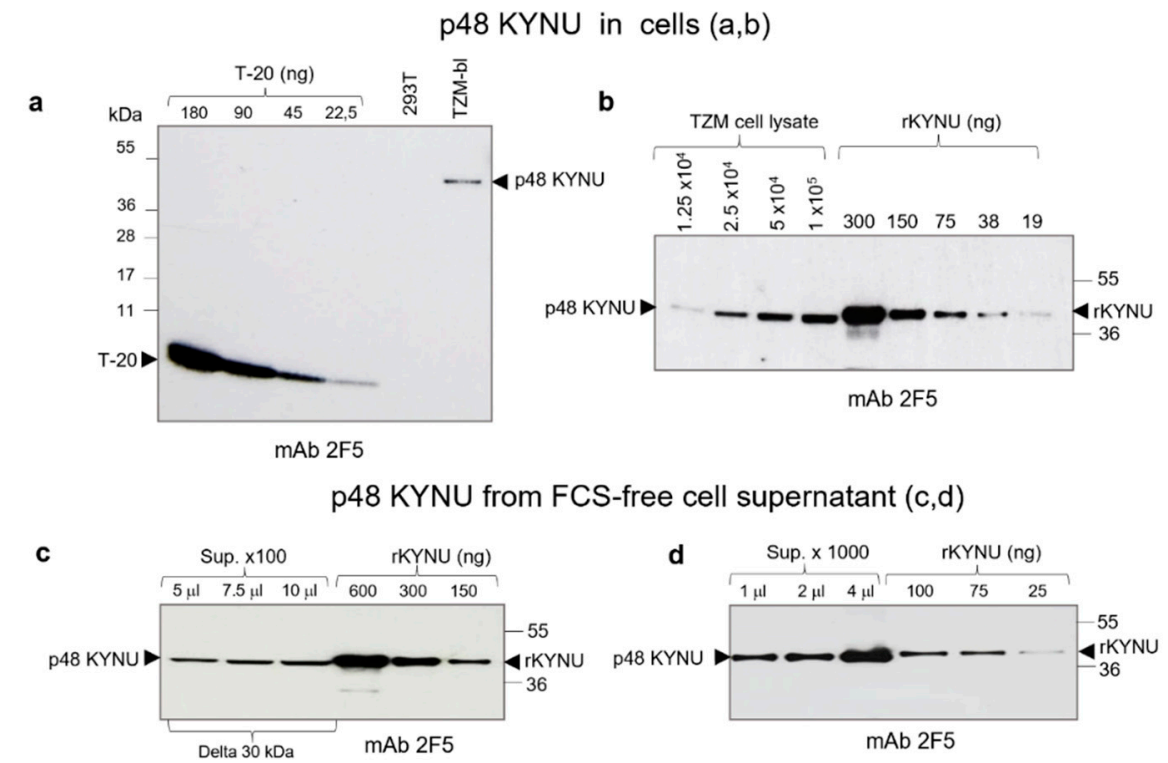

Figure 4. Estimation of p48 KYNU content in cells (a, b) and in cell supernatant (c, d). (a) Quantification of p48 KYNU in lysate from $5 \times 10^{4} \mathrm{TZM}$-bl cells was performed using a serial dilution of the T-20 peptide that contains the ELDKWA epitope. HEK293T cellular lysate from $5 \times 10^{4}$ cells was used as the negative control. It was estimated that approximately $32 \mathrm{ng}$ of p $48 \mathrm{KYNU}$ were present in $5 \times 10^{4}$ cells. That amount of p48 KYNU corresponds to $\sim 1.6 \times 10^{7}$ molecules $/$ cell. Western blot analysis was performed using mAb 2F5. (b) Quantification of p48 KYNU using the rKYNU as a reference. Serial two-fold dilutions of cellular lysates from $1 \times 10^{5}$ to $1.25 \times 10^{4}$ cells and serial two-fold dilutions of rKYNU from $300 \mathrm{ng}$ to $19 \mathrm{ng}$ (shown above) were examined. Using the Image software, it was shown that the amount of p48 KYNU in $1 \times 10^{5}$ cells was close to that of $130 \mathrm{ng}$ of rKYNU $\left(\sim 1.6 \times 10^{7}\right.$ molecules/cell). (c) Cell-free supernatant from TZM-bl cells harvested after $48 \mathrm{~h}$ and concentrated 100 times using $30 \mathrm{kDa}$ molecular weight cut-off concentrators (Sartorius, Stedim, Germany). Tracks: samples load $5 \mu \mathrm{L}$ (equivalent of $0.250 \mathrm{~mL}$ ); $7.5 \mu \mathrm{L}$ (equivalent of $0.750 \mathrm{~mL}$ ); $10 \mu \mathrm{L}$ (equivalent of $1 \mathrm{~mL}$ ); serial dilutions of rKYNU (amounts in $\mathrm{ng}$ are given below). (d) Estimation of p48 KYNU amount in pelleted FCS-free supernatant of TZM-bl cells concentrated 1000 times. Two-fold dilution of concentrated cell supernatant (concentration $\times 1000)$ from TZM-bl cells and serial dilutions of recombinant rKYNU were tested. Tracks: samples content $1 \mu \mathrm{L}$ (equivalent of $1 \mathrm{~mL}$ of pelleted supernatant); $2 \mu \mathrm{L}$ (equivalent of $2 \mathrm{~mL}$ ); $4 \mu \mathrm{L}$ (equivalent of $4 \mathrm{~mL}$ ); $100 \mathrm{ng}$ of $\mathrm{rKYNU}$, $75 \mathrm{ng} ; 50 \mathrm{ng} ; 25 \mathrm{ng}$. Using ImageJ, it was shown that $1 \mu \mathrm{L}$ contains $\sim 1.2 \times 10^{9}$ molecules of $\mathrm{p} 48$ KYNU. Blot was treated with mAb 2F5 $(2.5 \mathrm{mg} / \mathrm{mL})$.

Then, we performed titration of TZM-bl cell lysates using recombinant KYNU (rKYNU) as a reference (Figure $4 \mathrm{~b}$ ). Two-fold serial dilutions of TZM-bl lysates from $1.25 \times 10^{4}$, to $1 \times 10^{5}$ cells were compared with serial dilutions of rKYNU (from $300 \mathrm{ng}$ to $19 \mathrm{ng}$ ) (Figure $4 \mathrm{~b}$ ). Analysis of bands intensity was performed using the ImageJ software. The amount of p48 KYNU in the lysate from $1 \times 10^{5}$ cells corresponded to $130 \mathrm{ng}$ or $1.6 \times 10^{12}$ molecules of rKYNU. Dividing by the cell number it comes with $1.6 \times 10^{7}$ molecules/cell. So, likely because of the difference in references used and preparations the amount of $\mathrm{p} 48 \mathrm{KYNU}$ varies from 0.8 to $1.6 \times 10^{7}$ molecules/cell with a mean value of $1.2 \times 10^{7}$ molecules/cell. It is worth mentioning, that rKYNU used in this study has a 6-His tag, which increases the size of recombinant protein by $0.93 \mathrm{kDa}$. 
Next, we estimated the p48 KYNU content in FCS-free supernatant from TZM-bl cells. Ten milliliters of medium from $8 \times 10^{6} \mathrm{TZM}-\mathrm{bl}$ cells were harvested after $48 \mathrm{~h}$ and processed by low-speed centrifugation at $1200 \mathrm{~g}$ and $10,000 \mathrm{~g}$ for $10 \mathrm{~min}$. The supernatant was concentrated 100 times using a $30 \mathrm{kDa}$ molecular weight cut-off concentrator (Sartorius, Stedim, Göttingen, Germany). A serial two-fold dilution of p48 KYNU from concentrated supernatant and rKYNU (used as reference) were compared by Western blotting (Figure 4c). Estimation of the p $48 \mathrm{KYNU}$ content was accessed using ImageJ software. It was shown that $750 \mu \mathrm{L}$ of supernatant contained $150 \mathrm{ng}$ of $\mathrm{p} 48 \mathrm{KYNU}$ (or $0.2 \mathrm{ng} / \mu \mathrm{L}$ ). As one $\mathrm{mL}$ of cell medium contained KYNU that was released from $8 \times 10^{5}$ cells (1/10 of all cells). Dividing $150 \mathrm{ng}$ by $8 \times 10^{5}$ (cells) results in $0.187 \mathrm{pg} / \mathrm{cell}$. Using this calculation, we estimated the putative release of $\mathrm{p} 48 \mathrm{KYNU}$ from one well of the 96 well plate. Counting $4 \times 10^{4}-5 \times 10^{4}$ cells at the confluence, after $48 \mathrm{~h}$ from $7.5 \mathrm{ng}$ to $9.35 \mathrm{ng}$ of p $48 \mathrm{KYNU}$ might be released.

If counting interaction of $\mathrm{p} 48 \mathrm{KYNU}$ with $\mathrm{IgG}$ recognizing the ELDKWA epitope as 1:1 and considering that $1 \mathrm{ng}$ of $\mathrm{IgG}=4.3 \times 10^{9}$ molecules and $1 \mathrm{ng}$ of $\mathrm{p} 48 \mathrm{KYNU}=1.2 \times 10^{10}$ (or $0.6 \times 10^{10}$, if 1:2) molecules, that would result in a 2.8:1 (2.8 $\mathrm{ng}$ to $1 \mathrm{ng}$ ) ratio called further the "interaction factor" ("inf") of the IgG-p48 KYNU pair. If considering the "inf", $7.5 \mathrm{ng}$ to $9.35 \mathrm{ng}$ of p $48 \mathrm{KYNU}$ can interact with $21-26 \mathrm{ng}$ of $2 \mathrm{~F} 5$-like antibodies in a single well of the 96 well plate. It should be noted that cells are permanently producing p48 KYNU, thus the implication of the half-life parameter might not be so critical.

P48 KYNU was also isolated from FCS-free supernatant using ultracentrifugation. As above, TZM-bl cells were grown for $48 \mathrm{~h}, 10 \mathrm{~mL}$ of medium was processed, and the supernatant was centrifuged overnight at 170,000 g. The precipitate was recovered in PBS to achieve 1000 times concentrate (Figure $4 \mathrm{~d}$ ). As estimated by Western blotting, the concentration of p48 KYNU was from $125 \mathrm{ng} / \mathrm{mL}$ ( $0.156 \mathrm{pg} /$ cell) to $150 \mathrm{ng} / \mathrm{mL}(0.187 \mathrm{pg} /$ cell $)$ confirming the above-described estimations of extracellular p48 KYNU concentration. The procedure of protein isolation from SFM was repeated three times and the amounts of recovered protein varied insignificantly.

When using the pellet from SFM that was concentrated 1000 times the total protein load was $\sim 1 \mu \mathrm{g} / \mu \mathrm{L}$, while when using complete DMEM, it was about 10 times higher. Thus, p48 KYNU from SFM was selected for testing in the virus-neutralization (NT) assay.

\subsection{Evaluation of the $p 48 \mathrm{KYNU}$ Effect on $m A b s$ 2F5 and $4 E 10$ in NT Assays}

In the absence of a reference serum with a known proportion of the ELDKWA epitope recognizing 2F5-like neutralizing antibodies, precise estimation of p48 KYNU interference with corresponding antibodies and the impact on virus neutralization was difficult to achieve. In part, the problem was solved by mixing the mAbs $2 \mathrm{~F} 5$ (or 4E10) with normal human serum. These mixtures were used to monitor the effect of p48 KYNU in the NT assay. NT assays were performed using HIV- $1_{\text {pNL4-3 }}$ as a target (Figure $5 \mathrm{a}$ ) and it was performed on TZM-bl and Jurkat cells.

When the NT assay was performed on TZM-bl cells, an extra amount (4 ng or $2 \mathrm{ng} /$ well) of p48 KYNU isolated from pelleted supernatant was added to the reaction mixture. The reason to use additional p $48 \mathrm{KYNU}$ was to better approximate the protein effect on tested sera. In this assay, the initial concentration of mAb 2F5 was $100 \mathrm{ng} /$ well (Figure 5b). Since 7.5-9.35 ng (mean value $8.5 \mathrm{ng}$ ) of KYNU is released from one well of 96 well plate contains during $48 \mathrm{~h}$, together with applied protein, that would result in a maximum of $12.5 \mathrm{ng}(8.5 \mathrm{ng}+4 \mathrm{ng})$ of $\mathrm{p} 48 \mathrm{KYNU}$ in a single well. Considering the "inf" factor, that amount of KYNU can potentially interfere with up to $35 \mathrm{ng}$ or $35 \%$ of used antibodies. The obtained results were congruent with the predicted values although demonstrated even higher interference and indicated $80 \%$ and $65 \% 2 \mathrm{~F} 5$ neutralization reduction following the supplementation of the reaction mixture with 4 or 2 ng of p48 $\mathrm{KYNU}$, respectively (Figure $5 \mathrm{~b}$ ). In a parallel setting, a control dilution of mAb $2 \mathrm{~F} 5$ without p48 KYNU was performed. When mAb 4E10 were used in the NT assay together with p48 KYNU much less reduction of neutralization was observed (Figure S5). 


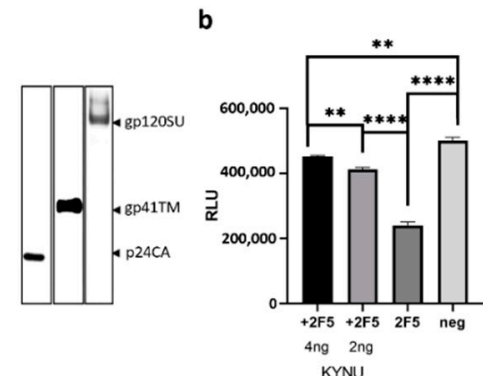

\section{C}

d

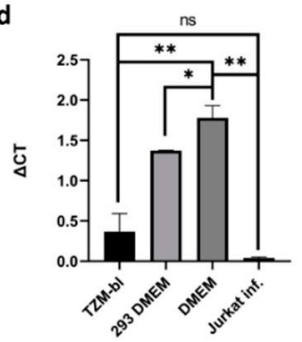

e

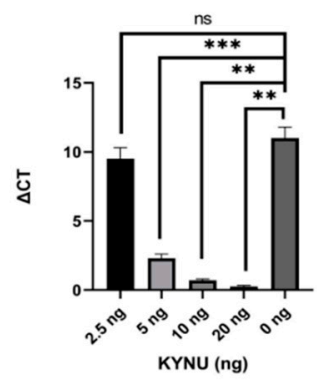

Figure 5. Neutralization of Mab 2F5 by p48 KYNU in HIV-1 NT assay. (a) HIV-1 preparation used in NT assays. Analysis of HIV-1 integrity by Western blotting (detection of p24 CA, gp41 TM, and gp120 SU). A Western blot analyses were performed using goat anti-p24CA (1:1000), goat anti-gp120 (1:1000) and Mab 2F5 (2.5 mg/mL). (b) NT assay on TZM-bl cells. Amounts of p48 KYNU added to the reaction mixture are shown below the columns. $100 \mathrm{ng}$ of $\mathrm{mAb} 2 \mathrm{~F} 5$ were added to two reaction mixtures. 2F5+KYNU-Mixture containing mAb 2F5 and 4 or 2 ng of extra p48 KYNU (indicated as +2F5). 2F5 mixture without additional p48 KYNU (indicates as 2F5). Neg.-Negative control, mixture without 2F5 and KYNU. RLU—Relative luciferase units. (c) NT assay on TZM-bl cells. 1 to 6-Serial two-fold dilution of the reaction mixture that initially contained $100 \mathrm{ng}$ of MAb 2F5 and 5 ng of p48 KYNU. 7-Reaction mixture without MAb 2F5 and p48 KYNU. Black columns-Mixtures without p $48 \mathrm{KYNU}$, grey columns-mixtures containing p $48 \mathrm{KYNU}$. The virus was taken to achieve MOI 0.5. (d) NT assay on Jurkat cells. $100 \mu \mathrm{L}$ of SFM from TZM-bl that contained app. $10 \mathrm{ng}$ of p48 KYNU was mixed with mAb 2F5 (100 ng/reaction). Each well contained $5 \times 10^{5}$ cells. Each culture medium was diluted 1:1 with complete RPMI 1640. A complete fresh DMEM medium was used as a negative control. The virus was added to achieve MOI of 0.5. The DNA was extracted from cells after $36 \mathrm{~h}$. TZM-bl—supernatant from TZM-bl cells (contained $10 \mathrm{ng}$ of KYNU), 293 DMEM-Cell-free supernatant from HEK293T cells, DMEM-Fresh complete DMEM with 10\% FCS; DNA from HIV-1 infected Jurkat cells was used as a positive control. Quantification of integrated proviruses was performed by real-time PCR. GAPDH was used as a housekeeping gene. Delta $C_{t}=C_{t}$ target- $C_{t}$ GAPDH. (e) NT assay on Jurkat cells using mAb 2F5 (100 ng/reaction) and increasing concentrations (from $2.5 \mathrm{ng}$ to $20 \mathrm{ng}$ ) of rKYNU. Amounts (ng) of applied rKYNU are given below the columns. Quantification of integrated proviruses was performed by real-time qPCR. GAPDH was used as a housekeeping gene. The virus infectious titer was $5 \times 10^{5}$. Experiments were performed in triplicates. Error bars represent standard deviation. An unpaired $t$-test was used to evaluate the statistical significance. The $p$ values less than 0.05 were regarded as statistically significant. Asterisks indicate: ${ }^{*} p<0.05 ; * * p<0.01 ; * * * p<0.001$; ${ }^{* * * *} p<0.0001$. $p$-value calculations were performed using GraphPad Prism version 8.4.3. (GraphPad Software, San Diego, CA, USA; RRID: SCR_002798) software.

Another NT test on TZM -bl cells was performed using a serial two-fold dilution of $\mathrm{mAb} 2 \mathrm{~F} 5$ with and without p48 KYNU. Initially, the concentration of mAb 2F5 was $100 \mathrm{ng}$ with $5 \mathrm{ng}$ of $\mathrm{p} 48 \mathrm{KYNU}$ (Figure 5c).

The NT assay on Jurkat cells (KYNU free cells) was performed to estimate the interaction of $\mathrm{mAb} 2 \mathrm{~F} 5$ with native $\mathrm{p} 48 \mathrm{KYNU}$ from the supernatant of TZM-bl cells. The efficacy of virus neutralization was assessed by quantifying integrated HIV-1 proviruses. Analysis of DNA by RT- PCR demonstrated that the supernatant containing p48 KYNU 
increased the number of integrated proviruses by more than one $\mathrm{Ct}\left(\Delta \mathrm{C}_{t} \sim 1\right)$ when compared to supernatant from HEK293T cells (Figure 5d). Thus, $10 \mathrm{ng}$ of p48 KYNU can reduce virus neutralization of mAb 2F5 (50 ng) by approximately two times. While the impact of supernatant from HEK293T cells on HIV-1 neutralization was insignificant.

Another NT assay was performed on Jurkat cells using commercial rKYNU. The goal of the assay was to estimate the amount of rKYNU that can inactivate $50 \mathrm{ng}$ of mAb 2F5 in one well of 96 well plate. To achieve this goal, an increasing concentration of rKYNU from $2.5 \mathrm{ng} /$ well to $20 \mathrm{ng}$ / well were added to reaction mixtures (Figure 5e) and, $48 \mathrm{~h}$ later, the DNA was extracted and analyzed for the proviruses as described above. In this case, the inactivation of $\mathrm{mAb} 2 \mathrm{~F} 5$ by $\mathrm{rKYNU}$ was prominent. For instance, when $5 \mathrm{ng}$ of rKYNU were used, the neutralization was reduced more than four times $\left(\Delta C_{t} \sim 2\right)$, while 20 ng of the rKYNU reduced neutralization by more than 1000 times $\left(\Delta C_{t} \sim 10\right)$. The stronger effect of rKYNU in NT assay on Jurkat cells was most likely attributed to the higher purity of rKYNU that does not contain cellular debris.

\section{Discussion}

The design of an efficient anti-HIV vaccine remains a principal, but a still inaccessible goal. The main hurdles on this way are-virus genetic variability and a dense glycan shield that includes $\sim 25$ glycans in SU and 7 in TM (4 glycans are in the ectodomain). Numerous approaches were used to obtain broadly neutralizing antibodies targeted the MPER of gp41TM and, in particular, the ELDKWA epitope-one of the most conserved regions.

Success in vaccine development depends not only on the selection of the right immunogen. Other important factors are the specificity and sensitivity of the reference systems, which are used for testing virus neutralization. One of the systems is the HeLa-derived TZM-bl reporter cell line, which is one of the most frequently used systems, that allow to quantify HIV infectious titer and to analyze the neutralization potential of anti-viral immune sera.

Here, we demonstrated that a TZM-bl cell expresses a protein (p48) that interferes with immune sera during HIV-1 neutralization assays. Based on biochemical parameters [32], immunoreactivity, and sequence, the protein was identified as L-kynurenine hydrolase (KYNU). Previously, using the immunoprecipitation approach and protein array studies, it has been shown, that mAb 2F5 recognizes KYNU via its ELDKWA epitope [34]. It should be emphasized that mAb 2F5 is highly specific and does not react with mutated ELD/EKWA epitope as in KYNU of opossum [34]. The implication of KYNU in reduced frequency of 2F5-like neutralizing antibodies in HIV-1 infected humans was also discussed [34].

KYNU is a member of the aspartate aminotransferase superfamily. It catalyzes the cleavage of kynurenine into anthranilic acid in the kynurenine pathway of tryptophan metabolism [31]. It is a plasma protein that has the highest level of expression in the liver [35]. To a significantly less degree, KYNU is expressed in the heart, brain, placenta, lung, liver, skeletal muscle, kidney, and pancreas. Interestingly, pro-inflammatory cytokines like IFN- $\gamma$ and TNF- $\alpha$ can notably increase KYNU expression in human fibroblasts [36]. KYNU is highly upregulated in patients with chronic inflammatory skin disease and tryptophan metabolites downstream of KYNU induce inflammatory gene expression [37].

Besides the TZM-bl cells, other cell lines are expressing KYNU (Human Protein Atlas; www.proteinatlas.org, accessed on 13 March 2016). Two of them U87MG (ATCC HTB-14, human glioblastoma epithelial cells) and A549 (ATCC CCL-185, human alveolar adenocarcinoma epithelial cells) demonstrated a significant level of KYNU expression with 309 and 169 transcripts per kilobase million (TPM), respectively. The level of KYNU expression in HeLa and HepG2 cells is lower-139 and 88 TPM, accordingly. A diverse level of KYNU expression in cells might be a result of aneuploidy and/or aberrations during alternative splicing of the transcript. It is likely, that KYNU expression in HeLa cells is not a property of all the HeLa strains. As a result of 70 years of cultivation, the HeLa cell proteome can vary from one lab to another [38]. Lysates from three strains of HeLa were examined by Western blotting; only HeLa CD4+LTR-Luc cell line expressed KYNU. The HeLa-CD4 strain 
HI-J was used for the TZM-bl cell design. Unfortunately, in the Human Protein Atlas, the parental HeLa strain that has been tested for the KYNU transcripts was not mentioned.

Identification of the p48 KYNU in the supernatant of TZM-bl cells was unanticipated and raised two questions. First, how the protein from cytoplasm is released from cells in the absence of the exportation signal and the transmembrane domain (showed using the Octopus topology program, http: / / octopus.cbr.su.se, accessed on 08 July 2016). Second, how important might be p48 KYNU interference with anti-ELDKWA immune sera in NT assay?

To access the first question, we suggested that the release of p48 KYNU might occur in a non-conventional way, which utilizes the intracellular vesicles secretion route. Such a release was proposed for the interleukin-1 $\beta$ (IL-1 $\beta$ ) [39]. It is also known, that shedding MVs are extracellular transporters for the cellular cargo and can deliver leaderless proteins [40]. This type of secretion was demonstrated for the IL-1 $\alpha$, fibroblast growth factor [41], and many other proteins, peptides, nucleic acids, and fragments of viruses.

To gain proves of possible non-classical secretion of KYNU we performed in silico analyzes using the SecretomeP2 program. The probability of non-classical secretion was estimated as 0.47 and that was close to the threshold level of 0.5 . However, when the $\mathrm{N}$-terminal fragments of the protein were examined an 11 amino acid (residues C21 to H31) long fragment at the N-terminal part of p48 KYNU demonstrated a 0.75 probability of non-classical secretion. Whether this stretch is a key element required for secretion remains to be determined. Moreover, it was found that filtration of TZM-bl FCS-free supernatant through the $0.45 \mu \mathrm{m}$ and $0.22 \mu \mathrm{m}$ filter and $20 \%$ sucrose cushion during ultra-centrifugation drastically reduced the amount of pelleted p48 KYNU (Figure 2c). However, if omitting $20 \%$ sucrose cushion and filtration, and performing overnight centrifugation, the amount of p48 KYNU increased significantly.

Taken together the results of confocal microscopy and centrifugation indicate that likely p48 KYNU is released from cells by two ways, as a free protein and in vesicles (presumably MVs) as a cargo. Otherwise, it can be efficiently liberated from vesicles following secretion.

The second question to answer was: "To what extent does the p48 KYNU inhibit sera, which contain 2F5-like neutralizing antibodies?

There was a considerable variability of gp41-derived immunogens and delivery strategies that were proposed to boost the 2F5-like neutralizing antibodies [42]. In terms of TZM-bl assay, it is likely that dependent on the antigen that has been used; the effect of KYNU on immune sera might vary significantly.

The HIV-1 gp41 is a strong immunogen that has six major antigenic determinants in the ectodomain [43-46]. Determinant I (residues 597-613), Determinant II, III, IV-(residues 641-683), Determinant V-(residues 512-579), Determinant VI-(residues 611-640) [44]. However, Determinant III in general and, the ELDKWA epitope in particular, are poorly exposed on the surface of the virion and are not immunodominant $[44,47,48]$. That is one of the reasons why neutralizing antibodies targeting the ELDKWA epitope in HIV-1 infected humans are scarce [49]. Such antibodies might appear only 20-30 months after virus infection [50]. However, delay with antibodies appearance may be explained not only by extended antibody maturation, because of a complex CDRH3 loop structure [51], but considering the obtained results, also by the time that is required to break natural tolerance against KYNU [34].

So, what type of immune serum might be predominantly affected by p48 KYNU in TZM-bl NT assay? For simplicity let's compare two hypothetical immune sera rose against different immunogens but recognizing the ELDKWA epitope. For example, the first group of sera was induced by immunization with the entire gp41TM or the gp41 ectodomain. The antigen may be administered in different formulations such as viruslike particles, liposomes, chimeric proteins, recombinant proteins, etc. In this case, the anti-MPER, including ELDKWA, immune responses might be relatively weak, because the domain is poorly immunogenic. However, the chance to obtain neutralizing antibodies 
recognizing required pre-hairpin conformation of gp41 [52-54] might not be zero. The second group of sera was obtained after immunization with peptide(s), that span the entire MPER (aa 662-683, acc. AF324493), or shorter peptides, containing the ELDKWA epitope as a part. In this case, the immune response might be directed predominantly against Determinant III including the ELDKWA epitope. Therefore, the overall immune response against this epitope might be relatively strong [55-57] (Morozov VA, personal communication), but antibodies are not neutralizing. Thus, if using the immunogens of the second type, the effect of KYNU might be low, as an outcome of a high amount of binding, but not neutralizing, antibodies. Nevertheless, compared to the first group of immunogens, because of the conformation, the chances to obtain neutralization antibodies using peptides are significantly lower, if any [16]. Therefore, we suggested that immune serum derived against the entire gp41 (or its large fragment) that contains a relatively low amount of anti-ELDKWA antibodies (recognizing and neutralizing) might be mostly "neutralized" by KYNU. It should be emphasized, that recognizing antibodies may also contribute to neutralization [58].

Valuation of KYNU interaction with immune serum-containing both recognizing and 2F5-like neutralizing antibodies might be more sophisticated. First, the interaction depends on the proportion of the 2F5-like neutralizing antibodies in a pool of antibodies recognizing the ELDKWA epitope. Second, the condition of serum, including the half-life of both tested immunoglobulins and KYNU should be considered. The last parameter is likely less critical, as during the assay period the p48 KYNU is permanently released from cells.

Collectively our data indicate that the amount of KYNU in a single well of the 96 well plate may be sufficient to neutralize approximately $26 \mathrm{ng}$ of 2F5-like neutralizing antibodies. Based on these values we obtained a graph displaying predicted interference of KYNU with the neutralization potency of sera (Figure 6).

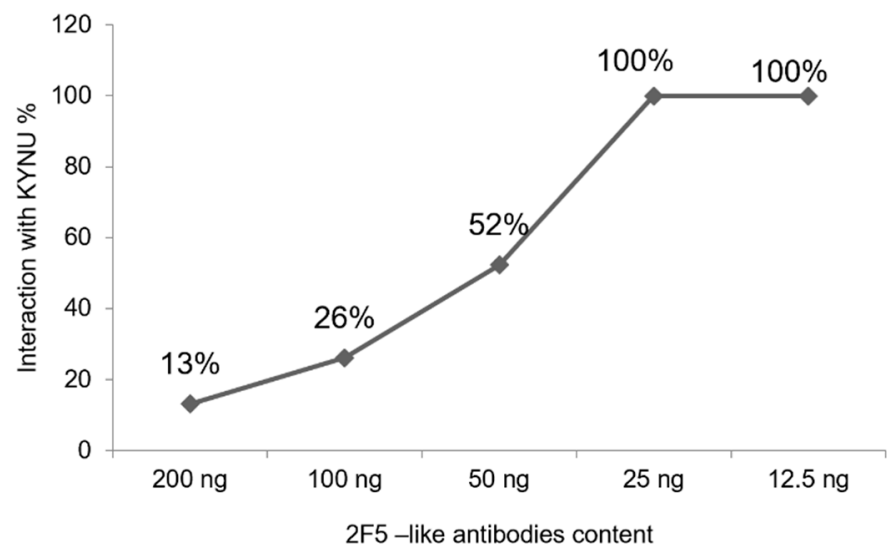

Figure 6. Estimation of p48 KYNU interaction with different amounts of 2F5-like antibodies. Estimation is based on the KYNU amount detected in the supernatant of TZM-bl cells (up to $9.35 \mathrm{ng}$ ) and the interference factor of 2.8. Here we consider only strong interactions between 2F5-like antibodies and p48 KYNU.

Thus, if the aliquot of tested antibodies contains less than 26 ng of ELDKWA-binding 2F5-like antibodies theoretically they all might be neutralized by KYNU. However, during NT assay a weak interaction of recognizing (not neutralizing) antibodies can reduce interaction of KYNU with neutralizing 2F5-like antibodies from the pool.

In this regard previously detected "weak neutralizing" sera (antibodies) should be retested using other detection systems.

\section{Materials and Methods}

\subsection{Cells and Cellular Lysates}

The established cell lines used in this study are listed in Table 1. 
TZM-bl cell line was obtained through the NIH AIDS Reagent Program, Division of AIDS, NIAID, NIH from Dr. John C. Kappes, Dr. Xiaoyun Wu, and Tranzyme Inc. (Durham, NC, USA). Adherent cells were maintained in DMEM and lymphoid cells in RPMI 1640 (Jurkat) supplemented with 10\% heat-inactivated fetal bovine serum (FBS), 1\% penicillin-streptomycin, and L-glutamine. TZM-bl cells were also grown on serum-free medium (SFM) using as a substitution LiforCell (Lifeblood medical, Inc., Adelphia, NJ, USA) and XerumFree (TNCBio, Eindhoven, The Netherlands) mediums supplemented with antibiotics and L-glutamine, as described above. Cell lines were tested for mycoplasma contamination using the MycoSensor PCR assay kit (Agilent Technologies, Santa Clara, CA, USA) and were found mycoplasma free.

To prepare cellular lysates cells were washed with phosphate-buffered saline (PBS), harvested and three times centrifuged at $1200 \mathrm{~g}$ for $5 \mathrm{~min}$. Obtained pellets were treated with NP40 lysis buffer (1\% NP-40; $150 \mathrm{mM} \mathrm{NaCl} ; 50 \mathrm{mM}$ Tris-HCl pH 8.0) containing protease inhibitor cocktail Complete (Roche, Mannheim, Germany). After incubation on ice for $10 \mathrm{~min}$, the lysates were centrifuged at 10,000 $\mathrm{g}$ for $10 \mathrm{~min}$. Supernatants were harvested and were kept frozen at $-80{ }^{\circ} \mathrm{C}$ before use. Stepwise separation of nuclear and cytoplasmic extracts from TZM-bl cells was performed according to the protocol of the Nuclear and Cytoplasmic Extraction Reagents kit (Thermo Fisher Scientific Inc., Waltham, MA, USA).

\subsection{Monoclonal Antibodies ( $m A b)$, Sera, Peptide, and Recombinant Protein}

Human mAbs 2F5 (core epitope ELDKWA) and 4E10 (core epitope NWFDIT) that targeted the membrane proximal external region (MPER) of gp41TM HIV-1 were from Polymun Scientific (Vienna, Austria). Mouse anti-gp41 monoclonal antibodies Chessie 8 (core epitope PDRPEG) was obtained from NIH AIDS reagent Program (Catalog \# 526) and also was kindly provided by Dr. George Lewis (Institute of Human Virology, University of Maryland, Baltimore, MD, USA). Rabbit anti-human kynureninase serum was obtained from GeneTex Inc. (Irvine, CA, USA). Monoclonal anti- $\beta$-actin clone AC-74 was from Sigma (St. Louis, MI, USA). Anti-human and anti-rabbit IgG- horse reddish peroxidase (HRP) conjugates were obtained from Dako Laboratories (Glostrup, Denmark). Baculovirusderived recombinant KYNU (rKYNU) was purchased from R\&D Systems Inc. (Abingdon, $\mathrm{UK})$. Mouse mAb anti-CD9 antibody was obtained from Invitrogen (Carlsbad, CA, USA). T-20 (Enfuvirtide, Fuzeon ${ }^{\circledR}$ ) a synthetic 36-residues peptide ( $\left.4.4 \mathrm{kDa}\right)$ corresponding to the amino acid residues 127-162 (GenBank acc. AF324493) of the heptad repeat 2 (including the ELDEKWA epitope) of gp41 HIV-1 was kindly provided by Dr. Schürmann (Charité, Campus Virchow-Klinikum, Berlin, Germany).

\subsection{Protein de-Glycosylation}

Protein deglycosylation was performed with Peptide-N-Glycosidase F (PNGase F) according to the protocol of the supplier (New England Biolabs, Inc., Ipswich, MA, USA), using a cytoplasmic fraction of TZM-bl cells enriched with p48 KYNU.

\subsection{SDS-PAGE, Native PAGE, and Western Blot Analyses}

Electrophoresis was performed in a gradient of 4-20\% SDS-PAG using Tris-Glycine buffer (Novex, Life Technologies, Carlsbad, CA, USA). Native PAGE was performed in 4-20\% gels using Tris-Glycine native running buffer and SDS-free gel loading buffer (Novex, Life Technologies, Carlsbad, CA, USA). Gels were calibrated using PageRuler Plus prestained protein ladder and MagicMark XP Protein Standard ( ThermoFisher Scientific, Waltham, MA, USA) or Western blot standard (Serva, Heidelberg, Germany). Proteins were transferred onto $0.2 \mu \mathrm{m}$ membrane (Protran BA83, Whatman GmbH, Dassel, Germany) at $45 \mathrm{~V}$ for $2 \mathrm{~h}$. Membranes were blocked with 6\% skimmed milk in PBS with $0.1 \%$ Tween 20 (blocking buffer) for $2 \mathrm{~h}$ at room temperature or overnight at $4{ }^{\circ} \mathrm{C}$. Incubation with mAbs diluted in blocking buffer $(1 \mu \mathrm{g} / \mathrm{mL})$ was performed for $2 \mathrm{~h}$ at room temperature. After five times washing (5 min each) in PBS with 0.1\% Tween 20 (PBS-Tween) membranes were incubated for $1 \mathrm{~h} 30 \mathrm{~min}$ with anti-human IgG-HRP conjugate (Dako Laboratories, 
Glostrup, Denmark) diluted 1:10 K in blocking buffer. The membranes were washed with PBS-Tween as indicated above, treated with Pierce ECL Western blotting substrate (Pierce, Rockford, Tempe, AZ, USA) for $1 \mathrm{~min}$, and exposed to Amersham Hyperfilm ECL (GE Healthcare Limited, Pollards Wood, UK).

\subsection{Confocal Microscopy}

TZM-bl and HEK293T cells were seeded on poly-L-lysine coated glass-bottom $\mu$ Dishes (Ibidi GmbH, Martinsreid, Germany). 24 h later the cells were washed with PBS and fixed with $2.5 \%$ paraformaldehyde for $10 \mathrm{~min}$. The cells were washed twice with PBS, permeabilized for 10 min with $0.5 \%$ Triton X-100, washed three times with PBS, and blocked for $1 \mathrm{~h}$ with blocking buffer $(1 \times$ PBS, $1 \%$ glycine, $0.1 \%$ Triton $\mathrm{X}-100)$ at room temperature. Then the cells were incubated for $1 \mathrm{~h}$ with $2 \mathrm{~F} 5(10 \mu \mathrm{g} / \mathrm{mL})$ diluted in blocking buffer, then rinsed three times in PBS with $0.1 \%$ Triton X-100 and stained with anti-human Alexa Fluor 488 conjugates (Invitrogen) diluted 1:200 in blocking buffer. Cells were left for $1 \mathrm{~h}$ at room temperature in the dark, rinsed three times with blocking buffer, and stained with DAPI as proposed by the manufacturer (NucBlue, Molecular Probes, Eugene, OR, USA). Images were captured using an LSM 780 fluorescent microscope (Carl Zeiss, Oberkochen, Germany) with an $\times 40$ oil emersion lens. The LSM 5 Image Examiner software was used.

\subsection{Isolation of 48 from Cell-Free Supernatant of TZM-bl Cells}

Supernatants from TZM-bl cells grown on complete DMEM or SFM were harvested after $48 \mathrm{~h}$, centrifuged at $1500 \mathrm{~g}$ and $10,000 \mathrm{~g}$ (each time for $10 \mathrm{~min}$ ) to eliminate cells and large cellular debris, respectively. The protein from SFM was concentrated using MWCO $30 \mathrm{kDa}$ filters (Sartorius Stedim Biotech, Germany). In addition, p48 was isolated by ultracentrifugation of cell-free supernatant that was centrifuged at $170,000 \mathrm{~g}$ for $18 \mathrm{~h}$ at $4{ }^{\circ} \mathrm{C}$. The pellets were suspended in PBS and were kept frozen at $-80^{\circ} \mathrm{C}$ before use.

\subsection{Extraction of RNA and DNA}

RNA was extracted using an RNeasy mini kit and RNase-free DNase set as recommended by the supplier (Qiagen $\mathrm{GmbH}$, Hilden, Germany). The RNA specimens were immediately used in reverse transcriptase reaction. DNA was extracted from $2 \times 10^{6}$ cells using a Blood and Tissue DNA isolation kit (Qiagen $\mathrm{GmbH}$, Hilden, Germany). Quantification of nucleic acids was performed using the NanoDrop spectrometer ND-1000.

\subsection{Reverse Transcriptase (RT)-PCR, Cloning, and Duplex Real-Time PCR}

The RT-PCR was performed using Titan one tube RT-PCR system (Roche Diagnostics, Mannheim, Germany) and primers described in Table 2. The RT reaction was carried out at $46^{\circ} \mathrm{C}$ for $40 \mathrm{~min}$, followed by denaturation at $94{ }^{\circ} \mathrm{C}$ for $2 \mathrm{~min}$ and 35 cycles of amplification with 1 min of elongation steps, as recommended by the supplier. Amplicons were purified from agarose gel using Invisorb Spin DNA Extraction kit (Stratec Molecular GmbH, Berlin, Germany), cloned into pCR4-TOPO (Invitrogen Life Technologies, Carlsbad, CA, USA), and sequenced. For the protein expression, the amplicons were cloned into the pTargeT mammalian expression vector (Promega Corp., Madison, WI, USA). Transformed JM109 cells (Promega, Corp., Madison, WI, USA) were seeded on LB/ampicillin plates and kept for $16 \mathrm{~h}$ at $37^{\circ} \mathrm{C}$. The plasmids were isolated using the PureYield plasmid mini preps system (Promega, Madison, WI, USA) and analyzed. Sequenced was performed using BigDye terminator kit V.3.1. (Applied Biosystems, Foster City, CA, USA). The selected clone further used for transfection was called "pTargeT KYNU". 
Table 2. Primers and probes.

\begin{tabular}{|c|c|c|c|}
\hline Name & Sequence $5^{\prime}-3^{\prime}$ & Nt. Position & Acc. Numbers \\
\hline HIV env F1 (7531) & 5'-CAGTGGACAAATTAGATGTTCATC & $7531-7554$ & AF324493 \\
\hline HIV env F2 (7580) & 5'-AGAGATGGTGGTAATAACAAC & $7580-7600$ & AF324493 \\
\hline HIV env R1 (8475) & 5'-GGCTCCGCAGATCGTCCCAGATAAGTG & $8501-8475$ & AF324493 \\
\hline HIV env R2 (8347) & 5'-TCCСТGCСТАAСТСТАTTCACT & $8347-8326$ & AF324493 \\
\hline HIV gag $\mathrm{F}$ & 5'-ATGGGTGCGAGAGCGTCGGTATT & $790-811$ & AF324493 \\
\hline HIV gag $\mathrm{R}$ & 5'-GGCTTCCTTGGTGTCTTTTACA & $1089-1068$ & AF324493 \\
\hline HIV gag (Probe) & FAM 5'-AATCCTGGCCTTTTAGAGACATCAG-BHQ & $928-950$ & AF324493 \\
\hline Kynu F & 5'-ATGGAGCCTTCATCTCTTGAG & $131-151$ & NM_003937 \\
\hline Kynu R & 5'-TGCTCCTGCATTTAAATA & $976-959$ & NM_003937 \\
\hline GAPDH F & 5'-CСАСТССТССАССТTTGAC-3' & $1058-1076$ & NM_002046.5 \\
\hline GAPDH R & 5'-ACCCTGTTGCTGTAGCCA-3' & 1159-1142 & NM_002046.5 \\
\hline GAPDH (Probe) & FAM 5'-TTGCCCTCAACGACCACTTTGTC-BHQ & 1090-1112 & NM_002046.5 \\
\hline
\end{tabular}

The HIV-1 proviruses in Jurkat cells were quantified by real-time PCR (primers shown in Table 2) using the HIV-1 gag gene as a target sequence and glyceraldehyde-3-phosphate dehydrogenase (GAPDH) gene for normalization $(\triangle \mathrm{Ct}=\mathrm{Ct}$ gene of interest $-\mathrm{Ct}$ GAPDH). Quantitative PCR was performed in duplicates in $25 \mu \mathrm{L}$ (final volume) using SensiFast no ROX kit (Bioline $\mathrm{GmbH}$, Luckenwalde, Germany). The thermal cycling profile was the following: enzyme activation at $95^{\circ} \mathrm{C}-3 \mathrm{~min}$ and 42 cycles $\left(95^{\circ} \mathrm{C} / 15 \mathrm{~s}-56{ }^{\circ} \mathrm{C} / 30 \mathrm{~s}-\right.$ $72{ }^{\circ} \mathrm{C} / 40 \mathrm{~s}$ ), and a final hold at $4{ }^{\circ} \mathrm{C}$. Fluorescence was measured using an Mx3005P Multiplex Quantitative PCR System (Stratagene, La Jolla, CA, USA).

\subsection{Transfection}

Transfection of the HEK293T cells $\left(5 \times 10^{5}\right)$ was performed in 6 well plates, using $2 \mu \mathrm{g}$ of pTargeT KYNU and $8 \mu \mathrm{L}$ of TransIT-293 transfection reagent (Mirus Bio LLC, Madison WI, USA) per well. $48 \mathrm{~h}$ later the cells were harvested, washed three times in PBS, lysed on ice for $10 \mathrm{~min}$ using NP-40 cell lysis buffer, and centrifuged at 10,000 $\mathrm{g}$ for $10 \mathrm{~min}$. The supernatant was harvested and used immediately in Western blot analysis, or it was kept frozen at $-80{ }^{\circ} \mathrm{C}$ before use.

\subsection{HIV-1 $1_{p N L 4-3}$ for the Neutralization (NT) Assay}

The HIV-1 for the NT assay was obtained by transient transfection of HEK293T cells with infectious molecular clone pHIV-1pNL4-3 ( $2 \mu \mathrm{g}$ of plasmid per $1 \times 10^{6}$ cells) using TransIT-293 transfected reagent (Mirus Bio LLC, Madison, WI, USA). $48 \mathrm{~h}$ post-transfection the supernatant was harvested, centrifuged at $1500 \times g(10 \mathrm{~min})$ and $10,000 \times g(10 \mathrm{~min})$, filtered through the $0.45-\mu \mathrm{m}$ filter, and stored at $-80{ }^{\circ} \mathrm{C}$ before use. The virus titer was estimated on TZM-bl cells in triplicates using serial ten-fold dilutions. An aliquot of the supernatant was ultra-centrifuged at 170,000 $\times g$ (SW41, Beckman, Pasadena, CA, USA) through a $20 \%$ sucrose cushion for $2 \mathrm{~h}$. The viral precipitate was diluted in PBS to gain 200 times concentrate. The preparations were tested for virus integrity by Western blot using anti-p24CA (capsid), anti-gp41TM, and anti-gp120SU, as described [9]. Virus infectivity was estimated on TZM-bl cells using 96-well plates and supernatants from two independent transfection experiments. Briefly, $10 \mu \mathrm{L}$ of the virus-containing supernatants from transfected cells were diluted in $90 \mu \mathrm{L}$ of complete medium, titrated by serial ten-fold dilutions, and added to the TZM-bl cells. After $24 \mathrm{~h}$ the medium was replaced. $24 \mathrm{~h}$ later cells were washed twice with PBS and fixed with $2.5 \%$ paraformaldehyde for $5 \mathrm{~min}$ at room temperature. Fixed cells were washed with PBS and stained with X-gal $(0.5 \mathrm{mg} / \mathrm{mL})$ in PBS with $5 \mathrm{mM}$ potassium ferricyanide, $5 \mathrm{mM}$ Potassium ferrocyanide, and $2 \mathrm{mM} \mathrm{MgCl}$. The reaction was developed in the dark for $3 \mathrm{~h}$ at $37^{\circ} \mathrm{C}$ or overnight at room temperature. Blue-stained $(\beta-\mathrm{Gal}+)$ cells were counted using a light microscope. Groups of blue-stained cells were counted as single foci of infection and wells containing $>5$ blue-stained cells were used for calculation. 


\subsection{NT Assay on TZM-bl and Jurkat Cells}

TZM-bl cells were seeded in 96-well flat-bottom plates. The NT assay was performed the next day when the monolayer was $\sim 80 \%$ confluent. The reaction mixture contained $10 \mu \mathrm{L}(5 \mu \mathrm{g} / \mathrm{mL}$ or $20 \mu \mathrm{g} / \mathrm{mL})$ of $\mathrm{mAb} 2 \mathrm{~F} 5,5 \mu \mathrm{L}$ of normal human serum, and different amounts of p48 KYNU (or rKYNU). The mixture was adjusted to $50 \mu \mathrm{L}$ with complete DMEM (TZM-bl cells) or RPMI 1640 (Jurkat cells). HIV-1 ${ }_{\text {NL4-3 }}$ (initial infectious titer $2 \times 10^{5} / \mathrm{mL}$ ) was diluted in complete DMEM to gain the MOI 0.5 and added to each reaction mixture. Incubation was performed for $1 \mathrm{~h}$ at $37^{\circ} \mathrm{C}$ and afterwards, the mixtures $(100 \mu \mathrm{L})$ were loaded on TZM-bl cells. After $48 \mathrm{~h}$ cells were washed twice with PBS and fixed with $2.5 \%$ paraformaldehyde for $15 \mathrm{~min}$ and washed in PBS. The luminescence was measured using the Bright-Glo ${ }^{\mathrm{TM}}$ Luciferase Assay System (Promega, Madison, WI, USA) and the signal was estimated using GloMax ${ }^{\circledR}-96$ microplate luminometer (Promega, Mannheim, Germany). The NT assay on Jurkat cells was performed as described above, but $2 \times 10^{5}$ cells were used for infection, and dilutions were prepared using a complete RPMI 1640 medium. $48 \mathrm{~h}$ post-infection the Jurkat cells were harvested and washed twice with PBS. Extraction of DNA was performed using Blood and Cell Culture DNA Mini kit (Qiagen $\mathrm{GmbH}$, Hilden, Germany). Proviruses were quantified by qPCR using the HIV-1 gag detection system.

\subsection{Software}

The Blast program (NCBI) was used for database search. Parameters of the oligonucleotides were examined using the OligoAnalyzer 3.1 (Integrated DNA Technologies, Coralville, IA, USA). The sequence alignments were performed using the software package Lasergene Version 10 (DNASTAR Inc., Madison, WI, USA). SecretomeP ${ }^{2}$ server (https: / / services.healthtech.dtu.dk/service.php?SecretomeP-2.0, accessed on 18 June 2016) was used to predict the possible way of KYNU secretion and UniProt resources (https:// www.uniprot.org/, accessed on 19 June 2016) were used for the structural analyses. ENCODE (https: / / www.encodeproject.org/experiments/ENCSR329MHM/, accessed on 19 June 2016) transcriptome analysis was used to estimate the KYNU expression level in HepG2, HeLa, U87MG, and A549 cells. Octopus topology program (Stockholm University, Stockholm Bioinformatics Center, Stockholm, Sweden) was used to estimate transmembrane topology.

\subsection{Statistics}

The experiments with statistical evaluation were performed at least in triplicates. An unpaired t-test was used to evaluate the statistical significance. The $p$ values less than 0.05 were regarded as statistically significant. Asterisks indicate: ${ }^{*} p<0.05 ;{ }^{* *} p<0.01$; ${ }^{* * *} p<0.001 ; * * * p<0.0001$. $p$-value calculations were performed using GraphPad Prism version 8.4.3. (GraphPad Software, San Diego, CA, USA; RRID: SCR_002798) software.

\section{Conclusions}

Here we demonstrated a vulnerability of the frequently used TZM-bl reporter cell line. The L-kynurenine hydrolase (KYNU), which contained the ELDKWA epitope recognized by $\mathrm{mAb} 2 \mathrm{~F} 5$ was detected in these cells and cell supernatant.

- $\quad$ The amount of p48 KYNU in TZM-bl cells is nearly 0.64 pg/cell

- $\quad$ About $0.19 \mathrm{pg} / \mathrm{cell}$ of p48 KYNU are released to cell supernatant after $48 \mathrm{~h}$

- $\quad$ From $7.5 \mathrm{ng}$ to $9.35 \mathrm{ng}$ of p48 KYNU can be released after $48 \mathrm{~h}$ from cells in one well of 96 well plate at the confluence.

- $\quad$ Released p48 KYNU can interact/inactivate 21-26 ng of 2F5-like antibodies in one well of 96 well plate.

Thus, 2F5-like antibodies in the TZM-bl NT assay can be partially or completely "inactivated" as a result of interference with the ELDKWA epitope of extracellular KYNU. The level of decrease depends on the proportion of neutralizing antibodies in the pool to anti- 
bodies recognizing the ELDKWA epitope. Consequently, the HIV-1 neutralization potency of previously tested sera reacting with gp41TM ELDKWA epitope might be underestimated.

Binding 2F5-like antibodies that were previously shown to recognize the ELDKWA epitope and demonstrated a so-called "week neutralization" of HIV in TZM-bl cell assay might contain significantly more neutralizing antibodies. In this regard revision of previously tested "weak" anti-ELDKWA sera might be essential and can shed light on the already designed immunogen that can induce 2F5-like antibodies.

Supplementary Materials: The following supporting information can be downloaded at https: //www.mdpi.com/article/10.3390/ijms23020641/s1.

Author Contributions: Conceptualization, V.M.; methodology, V.M., A.M., S.L.; software, A.M.; validation, V.M., A.M. and S.L.; formal analysis, V.M.; investigation, V.M., A.M., S.L.; resources, A.M., S.L.; data curation, V.M., A.M., S.L.; writing-original draft preparation, V.M.; writing-review and editing, V.M. and A.M.; visualization, V.M.; supervision, V.M., S.L.; project administration, V.M., S.L.; funding acquisition, A.M. All authors have read and agreed to the published version of the manuscript.

Funding: This work was funded by a grant from the Ministry of Science and Higher Education of the Russian Federation (agreement No. 075-15-2020-773).

Institutional Review Board Statement: Not applicable.

Informed Consent Statement: Not applicable.

Data Availability Statement: Data is available upon reasonable request.

Acknowledgments: We are grateful to Gregory Melikyan and his laboratory for valuable comments and discussions (Institute of Human Virology-IHV, Baltimore, MD, USA). We would like to thank Michael Laue, Kazimierz Madela, and Christoph Schaudinn (ZBS4, Robert Koch Institute, Berlin, Germany) for their help with confocal microscopy. Our special thanks to Martin Mielke (Robert Koch Institute, Berlin, Germany) for his advises and important contribution, that allows finalizing the work. We would like to acknowledge Joachim Denner (former P13 laboratory, Robert Koch Institute, Berlin, Germany) for critical remarks.

Conflicts of Interest: The authors declare no conflict of interest.

\section{References}

1. Landry, J.J.; Pyl, P.T.; Rausch, T.; Zichner, T.; Tekkedil, M.M.; Stutz, A.M.; Jauch, A.; Aiyar, R.S.; Pau, G.; Delhomme, N.; et al. The genomic and transcriptomic landscape of a HeLa cell line. G3 Genes Genomes Genet. 2013, 3, 1213-1224. [CrossRef]

2. Platt, E.J.; Wehrly, K.; Kuhmann, S.E.; Chesebro, B.; Kabat, D. Effects of CCR5 and CD4 cell surface concentrations on infections by macrophagetropic isolates of human immunodeficiency virus type 1. J. Virol. 1998, 72, 2855-2864. [CrossRef] [PubMed]

3. Kappes, J.; Wu, X. Cell-Based Method and Assay for Measuring the Infectivity and Drug Sensitivity of Immuno-Deficiency Virus. U.S. Patent 6,797,4622 B1, 10 February 2005.

4. Wei, X.; Decker, J.M.; Liu, H.; Zhang, Z.; Arani, R.B.; Kilby, J.M.; Saag, M.S.; Wu, X.; Shaw, G.M.; Kappes, J.C. Emergence of resistant human immunodeficiency virus type 1 in patients receiving fusion inhibitor (T-20) monotherapy. Antimicrob. Agents Chemother. 2002, 46, 1896-1905. [CrossRef]

5. Montefiori, D.C. Evaluating neutralizing antibodies against HIV, SIV, and SHIV in luciferase reporter gene assays. Curr. Protoc. Immunol. 2005, 64, 12.11.1-12.11.17. [CrossRef]

6. Polonis, V.R.; Brown, B.K.; Rosa Borges, A.; Zolla-Pazner, S.; Dimitrov, D.S.; Zhang, M.Y.; Barnett, S.W.; Ruprecht, R.M.; Scarlatti, G.; Fenyo, E.M.; et al. Recent advances in the characterization of HIV-1 neutralization assays for standardized evaluation of the antibody response to infection and vaccination. Virology 2008, 375, 315-320. [CrossRef]

7. Montefiori, D.C. Measuring HIV neutralization in a luciferase reporter gene assay. Methods Mol. Biol. 2009, 485, 395-405. [CrossRef]

8. Willey, R.; Nason, M.C.; Nishimura, Y.; Follmann, D.A.; Martin, M.A. Neutralizing antibody titers conferring protection to macaques from a simian/human immunodeficiency virus challenge using the TZM-bl assay. AIDS Res. Hum. Retrovir. 2010, 26, 89-98. [CrossRef]

9. Morozov, V.A.; Morozov, A.V.; Lagaye, S. Short communication: Simultaneous substitutions of V38M and N43T-N44K in the gp41 heptad repeat 1 (HR1) disrupt HIV type 1 gPr160 endoproteolytic cleavage. AIDS Res. Hum. Retrovir. 2010, $26,73-77$. [CrossRef] [PubMed] 
10. Yeh, W.W.; Rao, S.S.; Lim, S.Y.; Zhang, J.; Hraber, P.T.; Brassard, L.M.; Luedemann, C.; Todd, J.P.; Dodson, A.; Shen, L.; et al. The TRIM5 gene modulates penile mucosal acquisition of simian immunodeficiency virus in rhesus monkeys. J. Virol. 2011, 85, 10389-10398. [CrossRef]

11. Montefiori, D.C.; Karnasuta, C.; Huang, Y.; Ahmed, H.; Gilbert, P.; de Souza, M.S.; McLinden, R.; Tovanabutra, S.; LaurenceChenine, A.; Sanders-Buell, E.; et al. Magnitude and breadth of the neutralizing antibody response in the RV144 and Vax003 HIV-1 vaccine efficacy trials. J. Infect. Dis. 2012, 206, 431-441. [CrossRef]

12. Kramer, V.G.; Varsaneux, O.; Oliviera, M.; Colby-Germinario, S.P.; Mesplede, T.; Wainberg, M.A. Exposure to entry inhibitors alters HIV infectiousness and sensitivity to broadly neutralizing monoclonal antibodies. J. Acquir. Immune Defic. Syndr. 2014, 67, 7-14. [CrossRef]

13. Lai, R.P.; Hock, M.; Radzimanowski, J.; Tonks, P.; Hulsik, D.L.; Effantin, G.; Seilly, D.J.; Dreja, H.; Kliche, A.; Wagner, R.; et al. A fusion intermediate gp41 immunogen elicits neutralizing antibodies to HIV-1. J. Biol. Chem. 2014, 289, 29912-29926. [CrossRef] [PubMed]

14. Gombos, R.B.; Kolodkin-Gal, D.; Eslamizar, L.; Owuor, J.O.; Mazzola, E.; Gonzalez, A.M.; Korioth-Schmitz, B.; Gelman, R.S.; Montefiori, D.C.; Haynes, B.F.; et al. Inhibitory Effect of Individual or Combinations of Broadly Neutralizing Antibodies and Antiviral Reagents against Cell-Free and Cell-to-Cell HIV-1 Transmission. J. Virol. 2015, 89, 7813-7828. [CrossRef] [PubMed]

15. Santra, S.; Tomaras, G.D.; Warrier, R.; Nicely, N.I.; Liao, H.X.; Pollara, J.; Liu, P.; Alam, S.M.; Zhang, R.; Cocklin, S.L.; et al. Human Non-neutralizing HIV-1 Envelope Monoclonal Antibodies Limit the Number of Founder Viruses during SHIV Mucosal Infection in Rhesus Macaques. PLoS Pathog. 2015, 11, e1005042. [CrossRef]

16. Molinos-Albert, L.M.; Carrillo, J.; Curriu, M.; Rodriguez de la Concepcion, M.L.; Marfil, S.; Garcia, E.; Clotet, B.; Blanco, J. Anti-MPER antibodies with heterogeneous neutralization capacity are detectable in most untreated HIV-1 infected individuals. Retrovirology 2014, 11, 44. [CrossRef] [PubMed]

17. Gludish, D.W.; Boliar, S.; Caldwell, S.; Tembo, D.L.; Chimbayo, E.T.; Jambo, K.C.; Mwandumba, H.C.; Russell, D.G. TZM-gfp cells: A tractable fluorescent tool for analysis of rare and early HIV-1 infection. Sci. Rep. 2020, 10, 19900. [CrossRef]

18. Rindler, A.E.; Kuster, H.; Neumann, K.; Leemann, C.; Braun, D.L.; Metzner, K.J.; Günthard, H.F. A Novel High Throughput, Parallel Infection Assay for Determining the Replication Capacities of 346 Primary HIV-1 Isolates of the Zurich Primary HIV-1 Infection Study in Primary Cells. Viruses 2021, 13, 404. [CrossRef]

19. Pısıl, Y.; Shida, H.; Miura, T. A Neutralization Assay Based on Pseudo-Typed Lentivirus with SARS CoV-2 Spike Protein in ACE2-Expressing CRFK Cells. Pathogens 2021, 10, 153. [CrossRef] [PubMed]

20. Jin, H.; Tang, X.; Li, L.; Chen, Y.; Zhu, Y.; Chong, H.; He, Y. Generation of HIV-resistant cells with a single-domain antibody: Implications for HIV-1 gene therapy. Cell Mol. Immunol. 2021, 18, 660-674. [CrossRef]

21. Müller, T.G.; Zila, V.; Peters, K.; Schifferdecker, S.; Stanic, M.; Lucic, B.; Laketa, V.; Lusic, M.; Müller, B.; Kräusslich, H.G. HIV-1 uncoating by release of viral cDNA from capsid-like structures in the nucleus of infected cells. eLife 2021, 10, e64776. [CrossRef] [PubMed]

22. Takeuchi, Y.; McClure, M.O.; Pizzato, M. Identification of gammaretroviruses constitutively released from cell lines used for human immunodeficiency virus research. J. Virol. 2008, 82, 12585-12588. [CrossRef]

23. Platt, E.J.; Bilska, M.; Kozak, S.L.; Kabat, D.; Montefiori, D.C. Evidence that ecotropic murine leukemia virus contamination in TZM-bl cells does not affect the outcome of neutralizing antibody assays with human immunodeficiency virus type 1 . J. Virol. 2009, 83, 8289-8292. [CrossRef]

24. Sarzotti-Kelsoe, M.; Bailer, R.T.; Turk, E.; Lin, C.L.; Bilska, M.; Greene, K.M.; Gao, H.; Todd, C.A.; Ozaki, D.A.; Seaman, M.S.; et al. Optimization and validation of the TZM-bl assay for standardized assessments of neutralizing antibodies against HIV-1. $J$. Immunol. Methods 2014, 409, 131-146. [CrossRef]

25. Muster, T.; Steindl, F.; Purtscher, M.; Trkola, A.; Klima, A.; Himmler, G.; Ruker, F.; Katinger, H. A conserved neutralizing epitope on gp41 of human immunodeficiency virus type 1. J. Virol. 1993, 67, 6642-6647. [CrossRef]

26. Zwick, M.B.; Wang, M.; Poignard, P.; Stiegler, G.; Katinger, H.; Burton, D.R.; Parren, P.W. Neutralization synergy of human immunodeficiency virus type 1 primary isolates by cocktails of broadly neutralizing antibodies. J. Virol. 2001, 75, 12198-12208 [CrossRef] [PubMed]

27. Joos, B.; Trkola, A.; Kuster, H.; Aceto, L.; Fischer, M.; Stiegler, G.; Armbruster, C.; Vcelar, B.; Katinger, H.; Gunthard, H.F. Long-term multiple-dose pharmacokinetics of human monoclonal antibodies (MAbs) against human immunodeficiency virus type 1 envelope gp120 (MAb 2G12) and gp41 (MAbs 4E10 and 2F5). Antimicrob. Agents Chemother. 2006, 50, 1773-1779. [CrossRef]

28. Hessell, A.J.; Rakasz, E.G.; Tehrani, D.M.; Huber, M.; Weisgrau, K.L.; Landucci, G.; Forthal, D.N.; Koff, W.C.; Poignard, P.; Watkins, D.I.; et al. Broadly neutralizing monoclonal antibodies 2F5 and 4E10 directed against the human immunodeficiency virus type 1 gp41 membrane-proximal external region protect against mucosal challenge by simian-human immunodeficiency virus SHIVBa-L. J. Virol. 2010, 84, 1302-1313. [CrossRef]

29. Balazs, A.B.; Chen, J.; Hong, C.M.; Rao, D.S.; Yang, L.; Baltimore, D. Antibody-based protection against HIV infection by vectored immunoprophylaxis. Nature 2011, 481, 81-84. [CrossRef]

30. Lee, Y.; El Andaloussi, S.; Wood, M.J. Exosomes and microvesicles: Extracellular vesicles for genetic information transfer and gene therapy. Hum. Mol. Genet. 2012, 21, R125-R134. [CrossRef]

31. Phillips, R.S. Structure and mechanism of kynureninase. Arch. Biochem. Biophys. 2014, 544, 69-74. [CrossRef] 
32. Walsh, H.A.; Botting, N.P. Purification and biochemical characterization of some of the properties of recombinant human kynureninase. Eur. J. Biochem. 2002, 269, 2069-2074. [CrossRef]

33. Lima, S.; Khristoforov, R.; Momany, C.; Phillips, R.S. Crystal structure of Homo sapiens kynureninase. Biochemistry 2007, 46, 2735-2744. [CrossRef] [PubMed]

34. Yang, G.; Holl, T.M.; Liu, Y.; Li, Y.; Lu, X.; Nicely, N.I.; Kepler, T.B.; Alam, S.M.; Liao, H.X.; Cain, D.W.; et al. Identification of autoantigens recognized by the 2F5 and 4E10 broadly neutralizing HIV-1 antibodies. J. Exp. Med. 2013, 210, 241-256. [CrossRef]

35. Tanizawa, K.; Soda, K. Purification and properties of pig liver kynureninase. J. Biochem. 1979, 85, 901-906. [CrossRef]

36. Asp, L.; Johansson, A.S.; Mann, A.; Owe-Larsson, B.; Urbanska, E.M.; Kocki, T.; Kegel, M.; Engberg, G.; Lundkvist, G.B.; Karlsson, $\mathrm{H}$. Effects of pro-inflammatory cytokines on expression of kynurenine pathway enzymes in human dermal fibroblasts. J. Inflamm. 2011, 8, 25. [CrossRef]

37. Harden, J.L.; Lewis, S.M.; Lish, S.R.; Suarez-Farinas, M.; Gareau, D.; Lentini, T.; Johnson-Huang, L.M.; Krueger, J.G.; Lowes, M.A The tryptophan metabolism enzyme L-kynureninase is a novel inflammatory factor in psoriasis and other inflammatory diseases. J. Allergy Clin. Immunol. 2016, 137, 1830-1840. [CrossRef]

38. Liu, Y.; Mi, Y.; Mueller, T.; Kreibich, S.; Williams, E.; Van Drogen, A.; Borel, C.; Frank, M.; Germain, P.-L.; Bludau, I.; et al. Multi-omic measurements of heterogeneity in HeLa cells across laboratories. Nat. Biotechnol. 2019, 37, 314-322. [CrossRef] [PubMed]

39. Rubartelli, A.; Cozzolino, F.; Talio, M.; Sitia, R. A novel secretory pathway for interleukin-1 beta, a protein lacking a signal sequence. EMBO J. 1990, 9, 1503-1510. [CrossRef]

40. MacKenzie, A.; Wilson, H.L.; Kiss-Toth, E.; Dower, S.K.; North, R.A.; Surprenant, A. Rapid secretion of interleukin-1beta by microvesicle shedding. Immunity 2001, 15, 825-835. [CrossRef]

41. Prudovsky, I.; Mandinova, A.; Soldi, R.; Bagala, C.; Graziani, I.; Landriscina, M.; Tarantini, F.; Duarte, M.; Bellum, S.; Doherty, H.; et al. The non-classical export routes: FGF1 and IL-1alpha point the way. J. Cell Sci. 2003, 116, 4871-4881. [CrossRef]

42. Burton, D.R.; Desrosiers, R.C.; Doms, R.W.; Koff, W.C.; Kwong, P.D.; Moore, J.P.; Nabel, G.J.; Sodroski, J.; Wilson, I.A.; Wyatt, R.T. HIV vaccine design and the neutralizing antibody problem. Nat. Immunol. 2004, 5, 233-236. [CrossRef]

43. Gallaher, W.R.; Ball, J.M.; Garry, R.F.; Griffin, M.C.; Montelaro, R.C. A general model for the transmembrane proteins of HIV and other retroviruses. AIDS Res. Hum. Retrovir. 1989, 5, 431-440. [CrossRef]

44. Earl, P.L.; Broder, C.C.; Doms, R.W.; Moss, B. Epitope map of human immunodeficiency virus type 1 gp41 derived from 47 monoclonal antibodies produced by immunization with oligomeric envelope protein. J. Virol. 1997, 71, 2674-2684. [CrossRef]

45. Pietzsch, J.; Scheid, J.F.; Mouquet, H.; Klein, F.; Seaman, M.S.; Jankovic, M.; Corti, D.; Lanzavecchia, A.; Nussenzweig, M.C. Human anti-HIV-neutralizing antibodies frequently target a conserved epitope essential for viral fitness. J. Exp. Med. 2010, 207, 1995-2002. [CrossRef] [PubMed]

46. Opalka, D.; Pessi, A.; Bianchi, E.; Ciliberto, G.; Schleif, W.; McElhaugh, M.; Danzeisen, R.; Geleziunas, R.; Miller, M.; Eckert, D.M.; et al. Analysis of the HIV-1 gp41 specific immune response using a multiplexed antibody detection assay. J. Immunol. Methods 2004, 287, 49-65. [CrossRef]

47. Zolla-Pazner, S. Identifying epitopes of HIV-1 that induce protective antibodies. Nat. Rev. Immunol. 2004, 4, 199-210. [CrossRef]

48. Montero, M.; van Houten, N.E.; Wang, X.; Scott, J.K. The membrane-proximal external region of the human immunodeficiency virus type 1 envelope: Dominant site of antibody neutralization and target for vaccine design. Microbiol. Mol. Biol. Rev. MMBR 2008, 72, 54-84. [CrossRef]

49. Gray, E.S.; Madiga, M.C.; Moore, P.L.; Mlisana, K.; Abdool Karim, S.S.; Binley, J.M.; Shaw, G.M.; Mascola, J.R.; Morris, L. Broad neutralization of human immunodeficiency virus type 1 mediated by plasma antibodies against the gp41 membrane proximal external region. J. Virol. 2009, 83, 11265-11274. [CrossRef]

50. McMichael, A.J.; Borrow, P.; Tomaras, G.D.; Goonetilleke, N.; Haynes, B.F. The immune response during acute HIV-1 infection: Clues for vaccine development. Nat. Rev. Immunol. 2010, 10, 11-23. [CrossRef]

51. Lutje Hulsik, D.; Liu, Y.Y.; Strokappe, N.M.; Battella, S.; El Khattabi, M.; McCoy, L.E.; Sabin, C.; Hinz, A.; Hock, M.; Macheboeuf, P.; et al. A gp41 MPER-specific llama VHH requires a hydrophobic CDR3 for neutralization but not for antigen recognition. PLoS Pathog. 2013, 9, e1003202. [CrossRef]

52. Frey, G.; Peng, H.; Rits-Volloch, S.; Morelli, M.; Cheng, Y.; Chen, B. A fusion-intermediate state of HIV-1 gp41 targeted by broadly neutralizing antibodies. Proc. Natl. Acad. Sci. USA 2008, 105, 3739-3744. [CrossRef] [PubMed]

53. Frey, G.; Chen, J.; Rits-Volloch, S.; Freeman, M.M.; Zolla-Pazner, S.; Chen, B. Distinct conformational states of HIV-1 gp41 are recognized by neutralizing and non-neutralizing antibodies. Nat. Struct. Mol. Biol. 2010, 17, 1486-1491. [CrossRef]

54. Vassell, R.; He, Y.; Vennakalanti, P.; Dey, A.K.; Zhuang, M.; Wang, W.; Sun, Y.; Biron-Sorek, Z.; Srivastava, I.K.; LaBranche, C.C.; et al. Immunogens Modeling a Fusion-Intermediate Conformation of gp41 Elicit Antibodies to the Membrane Proximal External Region of the HIV Envelope Glycoprotein. PLoS ONE 2015, 10, e0128562. [CrossRef]

55. Wang, Z.; Liu, Z.; Cheng, X.; Chen, Y.H. The recombinant immunogen with high-density epitopes of ELDKWA and ELDEWA induced antibodies recognizing both epitopes on HIV-1 gp41. Microbiol. Immunol. 2005, 49, 703-709. [CrossRef]

56. Cao, Y.; Chen, Y. Characterization of Antibody Responses Against the 2F5 Epitope ELDKWA Using HIV-1 Env-Mediated Membrane Fusion and Neutralization Assays. Tsinghua Sci. Technol. 2010, 15, 447-451. [CrossRef] 
57. Strasz, N.; Morozov, V.A.; Kreutzberger, J.; Keller, M.; Eschricht, M.; Denner, J. Immunization with hybrid proteins containing the membrane proximal external region of HIV-1. AIDS Res. Hum. Retrovir. 2014, 30, 498-508. [CrossRef] [PubMed]

58. Holl, V.; Peressin, M.; Decoville, T.; Schmidt, S.; Zolla-Pazner, S.; Aubertin, A.M.; Moog, C. Nonneutralizing antibodies are able to inhibit human immunodeficiency virus type 1 replication in macrophages and immature dendritic cells. J. Virol. 2006, 80, 6177-6181. [CrossRef] 